\title{
Anatomy of the dromedary head skeleton revisited
}

\author{
EL ALLALI, K., ACHAÂBAN, M. R. and OUASSAT, M.
}

\begin{abstract}
Comparative Anatomy Unit-URAC49, Department of Biological and Pharmaceutical Veterinary Sciences, Hassan II Agronomy and Veterinary Institute, B.P.6202 Rabat-Instituts Rabat 10101, Morocco

*E-mail: khalid_elallali@yahoo.fr
\end{abstract}

\begin{abstract}
Introduction: Dromedary Camel is known for its specific adaptation to the hostile environment of desert areas. Hence, it is a very interesting model to consider for biological and veterinary sciences. A good knowledge of camel head osteology is relevant to overcome the lack of accurate data useful for comparative anatomy, radiology and clinical practice. Methods: The present work studied the osteology of the camel skull at different age and investigates blood vessels and nerves passing through its foramina. Results: The obtained data show similarities with domestic mammals but also several peculiarities. These include particularly; the existence of an extensive temporal fossa; a prominent external sagittal crest in the adults which is replaced by a large parietal planum in the youngest; the supra-orbital foramina give access only to the frontal vein and thus cannot be used for the nerve block and anesthesia of the upper eyelids; supplementary foramens including, a retroarticular, a lateral sphenopalatine, an accessory maxillary and a lacrimal fontanel were described for the first time. Unlike that reported in the literature, the lacerate foramen is covered by a fibro-cartilaginous layer; whereas the carotid foramen is located caudally to the jugular foramen. The hyoid lingual process is lacking while the epibyoideum is well developed. The mandibular symphysis is well extended reaching $13.2 \pm 0.8 \mathrm{~cm}$. Also, the literature controversy concerning the lower jaw dental formula was discussed and elucidated: I3-C1-PM2-M3. Conclusion: This study provides a deep anatomy description of the camel skull. The presented results are important for comparative anatomy and clinical investigations.
\end{abstract}

Keywords: camel, skull osteology, foramina, vessels, nerves.

\section{Introduction}

In arid and desert areas, animals are exposed to different levels of the extreme conditions of the environment. Unlike small desert animals, camel (Camelus dromedarius), which is continuously exposed to heat, solar radiation, lack of water, dryness and scarcity in food availability, present various adaptive strategies in order to cope with this specific and drastic environment. In spite of these harsh conditions, the dromedary camel is also capable of maintaining important productions such as meat, milk, hair and wool (BENGOUMI and FAYE, 2002). These exceptional performances result from its unique behavioural, anatomical, and physiological peculiarities (SCHMIDT-NIELSEN, SCHMIDT-NIELSEN, JARNUM et al., 1957; WILSON, 1984; EL ALLALI, ACHAÂBAN, BOTHOREL et al., 2013; BOUÂOUDA, ACHAÂBAN, OUASSAT et al., 2014) which makes the dromedary camel, one of the most important models for studying adaptation to extreme environments. Even though, the number of published articles per year concerning this species remains very low: averaging only 98 papers per year (RATHINASABAPATHY and RAJENDRAN, 2013) as compared to 1.5 million articles per year for the whole disciplines and species (1,504,600 within 2009: JINHA, 2010).

Nowadays, literature concerning comparative anatomy of dromedary camel especially osteology is still rare and scattered. Description of camel anatomy by Chauveau (1879), Lesbre (1903), Müller (1962) and then by Smuts and Bezuidenhout (1987) constitutes the main Anatomical references for veterinary research and lecturing programs concerning this species. Related skull anatomy description was completed by several other studies: Indeed, Al-Sagair and Elmougy (2002) gave an exhaustive morphometric description of post-natal skull development and Rashid and Kausar (2005) compared camel skull to that of others domestic mammals. More recently YAHAYA team studied different morphometric aspects of camel skull (YAHAYA, OLOPADE and KWARI, 2011; YAHAYA, OLOPADE, KWARI et al., 2012a, b, c).

However, the related literature is still lacking details of all anatomical aspects of camel skull. In addition, because of some inconsistencies, a reinvestigation of the anatomy of the camel head skeleton was therefore undertaken. Thus, the present work is giving a detailed description, clarifying and completing previous findings, is also reporting new morphological aspects such as nerves and blood vessels paths through foramina and finally is comparing skull features of young and adult camels. This present study is a contribution to fill a gap in the field of veterinary comparative anatomy.

\section{Materials and Methods}

Thirty camel skulls of different ages of both sexes were carefully examined. Skulls consist of two groups. The first group included 20 specimens of the Comparative Anatomy Unit collection (Veterinary School of Rabat, Morocco) and was used for osteological description while the second group included the 10 other skulls prepared from camel heads obtained from local slaughterhouse and was used to investigate different grooves and foramina paths giving access to blood vessels and nerves. The concerned specimens were immediately 
fixed after slaughtering using intra-carotid infusion of a $10 \%$ formalin solution and then were carefully dissected. Arteries were plasticized either with injection of 5-10\% Rhodopas $\left(\right.$ Prolabo $^{\odot}$, France) solution, prepared in acetone and stained by Alum Carmine or using a mixture of gypsum powder and ultramarine blue pigment (PB29).

Anatomical description involved a study of the skull as a whole, the mandible and finally the hyoid apparatus. Different views of the skull external conformation was first studied, then, the internal conformation was investigated through different sections. Each view was divided in three subdivisions: cranium, intermediate and facial.

\section{Results and Discussion}

The overall obtained data show similarities with others domestic mammals but also several peculiarities in the camel head osteology.

\subsection{Compartative osteology of the skull}

The external conformation of the skull includes the study of the dorsal, ventral and both lateral views as well as the description of the base (caudal or nuchal view) and the apex (rostral view).

\subsubsection{Dorsal view (Figure 1)}

Cranium region: This surface is bordered by a prominent nuchal crest (Crista nuchae) and shows a major development of an external sagittal crest (Crista sagittalis externa) which delimits on each side an extensive and deep temporal fossa
(Fossa temporalis) (Figure la). Accordingly, the external sagittal crest reaches it maximum development in adults and is also more prominent in dromedary than in Bactrian camels. The temporal fossa shows 3 to 4 temporal foramina. Although anatomical differences between young and adults camel skeleton have been evoked in the literature particularly by Lesbre (1903), a detailed description of morphological variations within the dorsal surface of the camel cranium according to the age is reported hereafter (Figure lb-d). Indeed, in young camels, the external sagittal crest is quit erased showing instead a large flat surface corresponding to planum parietale, which is bordered laterally by two lineae temporalis (Figure $1 \mathrm{~b}$ ). Thus, the skull of young camel appears different from that of adult camel and can be confounded with that of other species. As the animal grows up, the two lineae temporalis merge gradually, leading to (1) a caudo-rostral narrowing of this planum, (2) its shifting forward and (3) a progressive formation and rising of the external sagittal crest (Figure 1b, c). The emergence of external sagittal crest starts from the external occipital protuberance (Protuberantia occipitalis externa) and extends rostrally by a divergence of the two lineae temporalis behind the parieto-frontal suture. The external sagittal crest becomes more prominent with age and appears in the adult male as a real spine. Therefore, also reported by Smuts and Bezuidenhout (1987), the camel skull outline appears closer to that of equine. Similarities exist also in the age related changing of the cranium surface. However the planum of the foal is rather less developed than in both young and adult camels; while in the horse, the external sagittal crest is less prominent and the temporal fossa is smaller.
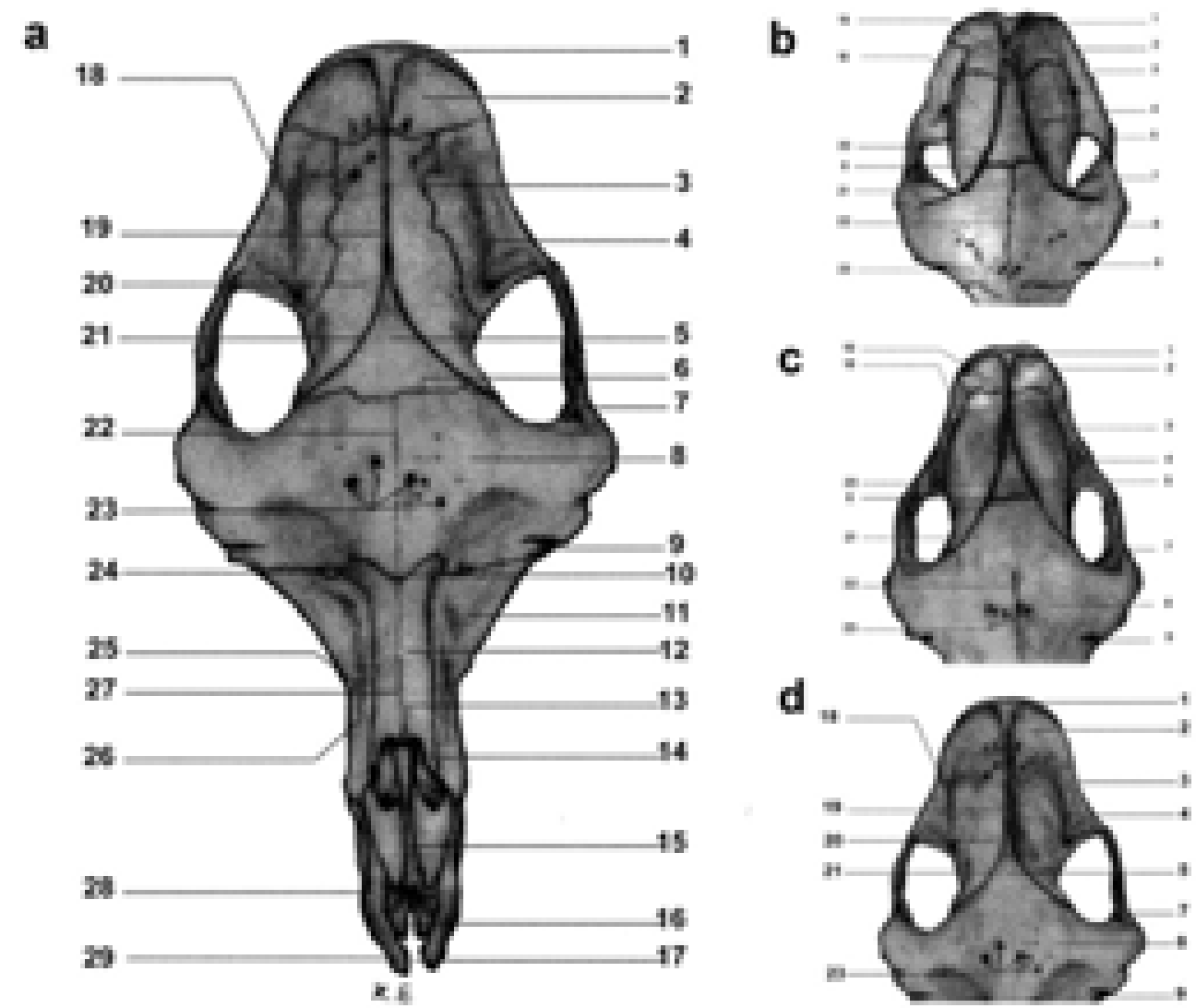

Figure 1. Dorsal view of camel skull. a: 7-years-old male; b: 2-years-old male; c: 4-years-old male; d: 13-years-old male (See Appendix A for definitions). 
Intermediate region: This region extends from the parieto-frontal suture to the fronto-nasal suture (Figure la). The frontal surface shows a median concavity in which the bone is pierced on each side by one or two main supra-orbital foramina (Foramen supraorbitale) accompanied as well by numerous accessory ones. These holes were previously described by Chauveau (1879) as the openings of intra-bony ducts. In some skulls, a reduced supraorbital groove can be seen (sulcus supraorbitalis) but less developed than that reported in swine and ruminants (SISSON and GROSSMAN, 1953). However, this groove is absent in Bactrian camel (LESBRE, 1903). The supra-orbital margin (Margo supraorbitalis) expands rostro-medially by a notch, the Incisura infratrocblearis (Figure 1). This latter shows one or two small openings which serve as a pathway for the infra-trochlear nerve (Nervus infratrochlearis) and homonyms blood vessels.

Facial region: The facial part of the camel skull is less developed than in the horse. The Dorsum nasi is flunked in front of the orbit and bordered in each side by a depressed concavity. The nasal bone (Os nasale), is reduced and appears larger at its end than at its base. Thus, the rostral nasal process (Processus nasalis) which is well developed in horse, in small ruminants and swine (BARONE, 1976) is not apparent in the camel. However, there is, instead, two small processes delimiting a notch; the medial one is shorter and forms a tiny median concavity with its opposite of the other side, while the lateral one is larger. Similar description was reported by Chauveau (1879) in dromedary camel and by Lesbre (1903) in the Bactrian camel. No openings have been observed on the lateral side of the nasal bone which disagrees with the finding of Yahaya, Olopade, Kwari et al. (2012a), who reported a bilateral and very large $(2.9 \times 0.4 \mathrm{~cm}$ and $3.5 \times 0.3 \mathrm{~cm})$ openings in the Dorsum nasi of camel. Such openings exist also in the Red Sokoto goat (OLOPADE, ONWUK, KWARI et al., 2006) but seem to be uncommon in the camel.

The rostral opening of the nose is peculiar in the camel involving the maxillary bone (Maxilla) which separates, in adults, the nasal bone from the incisive bone (Os incisivum) (see below). Furthermore, deeper in this opening, appears, (1) a special shaped vomer bone (Vomer), resembling to a half duct and (2) the edge of the ventro rostral concha
(Figure 1). More rostrally, there is no fusion of incisive bones showing therefore an opening of the interincisive fissura (Fissura interincisiva) as the case in swine and ruminants (GETTY, 1975a, b; BARONE, 1976).

\subsubsection{Lateral view}

Cranium region: The caudal part of this view shows a large and extensive temporal fossa and a prominent external sagittal crest as described above (Figure 2). This crest discloses a rostral convexity and a caudal concavity. The nuchal crest is well developed and continues rostrally by an elevated temporal crest (Crista temporalis) and ventro-rostrally by a mastoid crest (Crista supramastoidea) which joins the mastoid process (Processus mastoideus) (Figures 2 and 3 ). The mastoid crest and process are both parts of petrous portion (Pars petrosa) of the temporal bone.

The tympanic portion (Pars tympanica) of the temporal bone (Os temporale) is intercalated between: 1) The jugular process (Processus jugularis) of occipital bone (Os occipitale), caudally; 2) The retrotympanic process (Processus retrotympanicus) of the squamous portion (Pars squamosa) of temporal bone, dorsocaudally; and 3 ) the retroarticular process (Processus retroarticularis) of the squamous portion of temporal bone, rostrally.

This tympanic portion shows (Figure 2): 1) a tympanic bulla (Bulla tympanica), which is slightly thick, flattened and characterized by the existence of a short main muscular process (Processus muscularis). In all camel skulls examined in this study, we observed the existence of one or two other accessory muscular processes which have not been described elsewhere including the Bactrian camel in which Lesbre (1903) reported only a unique muscular process. And 2) a very well developed vaginal process (Vagina processus stylodei) (see details in the description of the ventral view).

The external acoustic meatus (Meatus acusticus externus) is enclosed and totally surrounded by the tympanic portion. In front of this meatus, we noticed the existence of the opening of Foramen retroarticulare. This later corresponds to the aperture of the meatus temporalis which, in the camel, is connected to another medial opening on the ventral view and medially to the retroarticulare process. This means that, in the

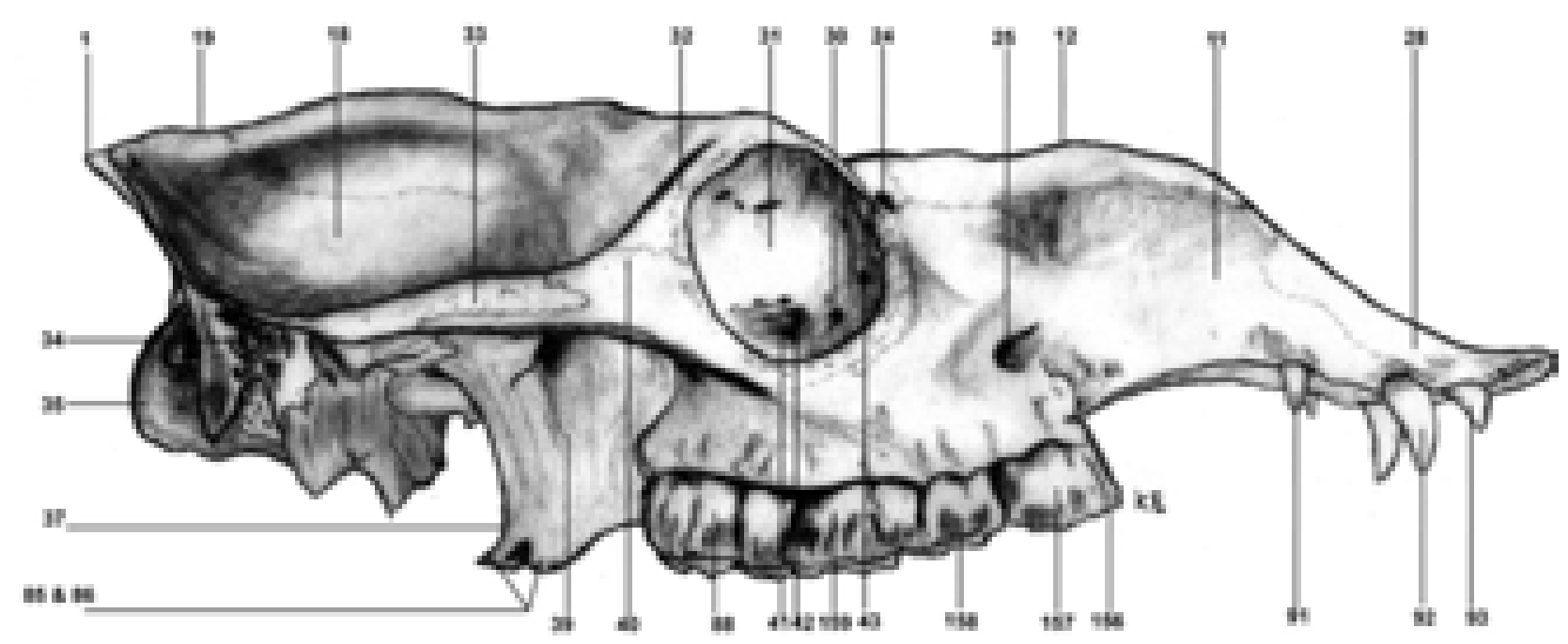

Figure 2. Lateral view of adult male skull (See Appendix A for definitions). 
camel, there are medial and lateral retroarticulare foramina. Likewise, Lesbre (1903) reported also 1, 2 or 3 holes behind the retroarticular process which are all connected to the temporal meatus. This seems to be a peculiarity of the camelus genre since in other domestic animals (horse, ruminants, dog) this temporal meatus, when it exists (BARONE, 1976), starts in the cranium near the internal occipital protuberance (Protuberantia occipitalis interna) continues in the transverse sinus and then into the petro-squamous sinus and proceeds between the squama and the pyramid of the temporal bone toward a unique retroarticulare foramen (SISSON and GROSSMAN, 1953; BARONE, 1976; WYSOCKI, 2002). This opening in the Bison is divided into several or even a dozen foramina of different sizes, situated below or on the zygomatic arch: 1 to 4 main retroarticular foramina and several additional ones (WYSOCKI, 2002).

Furthermore, we also noticed that the direction of this external acoustic meatus changes with age. Indeed, in young

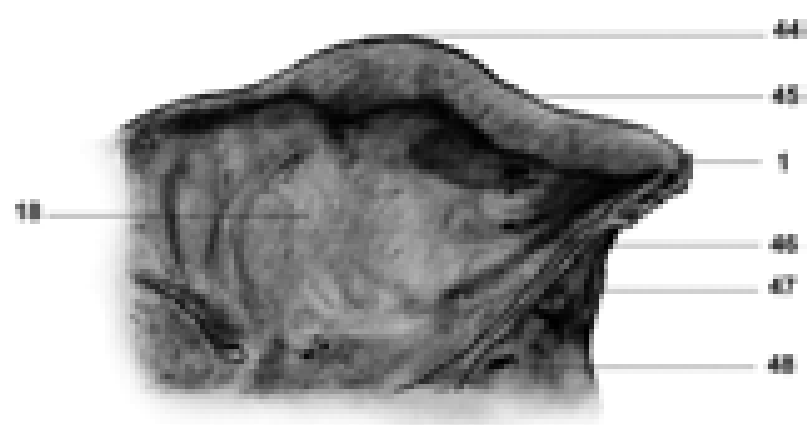

Figure 3. Details of caudal part of lateral view of adult male skull (See Appendix A for definitions). camels, this meatus opens dorsally or dorso-caudally while in the adult ones, it is rather directed latero-ventrally.

The squamous portion of the temporal bone contributes by its zygomatic process (Processus zygomaticus) in the formation of a well-developed zygomatic arch (Arcuszygomaticus) as it fuses to the temporal process (Processus temporalis) of the zygomatic bone (Os zygomaticum) (Figure 4). We demonstrated above that this fusion occurs differently depending on the age of the camel. Thus, in young camel, the zygomatic process of the temporal bone forms a long and pointed tip which penetrates deeply into the caudal side of the temporal process of the zygomatic bone, whereas in the adult camel, the zygomatic process of temporal bone is displaced caudally and its extremity is rather shorter and less peaked (Figure 5).

Like in ruminants (GETTY, 1975b; BARONE, 1976), the zygomatic bone of the camel presents an important frontal process (Processus frontalis). This later fuses with the zygomatic process (Processus zygomaticus) of the frontal bone (Os frontale) and forms a connecting bridge above the limit between the temporal and orbital fossa. We also observed that the fusion level of these two processes changes with the age of the animal. Indeed, in young camel, it occurs at the third ventral part of this bone's bridge while in the adult the fusion is displaced to the middle (Figure 5). Moreover, the two processes of the zygomatic bone are more prominent in the adult, pushing the frontal bone to the dorsal direction and the temporal bone caudally.

Intermediate region: This region is also known as orbital region including the orbit cavity and pterygopalatine fossa (Fossa pterygopalatina). The orbit cavity in the camel is mainly constituted by the frontal, the lacrimal (Os lacrimale), the zygomatic and the maxillary bones. The orbit apex of each orbit is formed by: (1) the wing of the pre-sphenoid

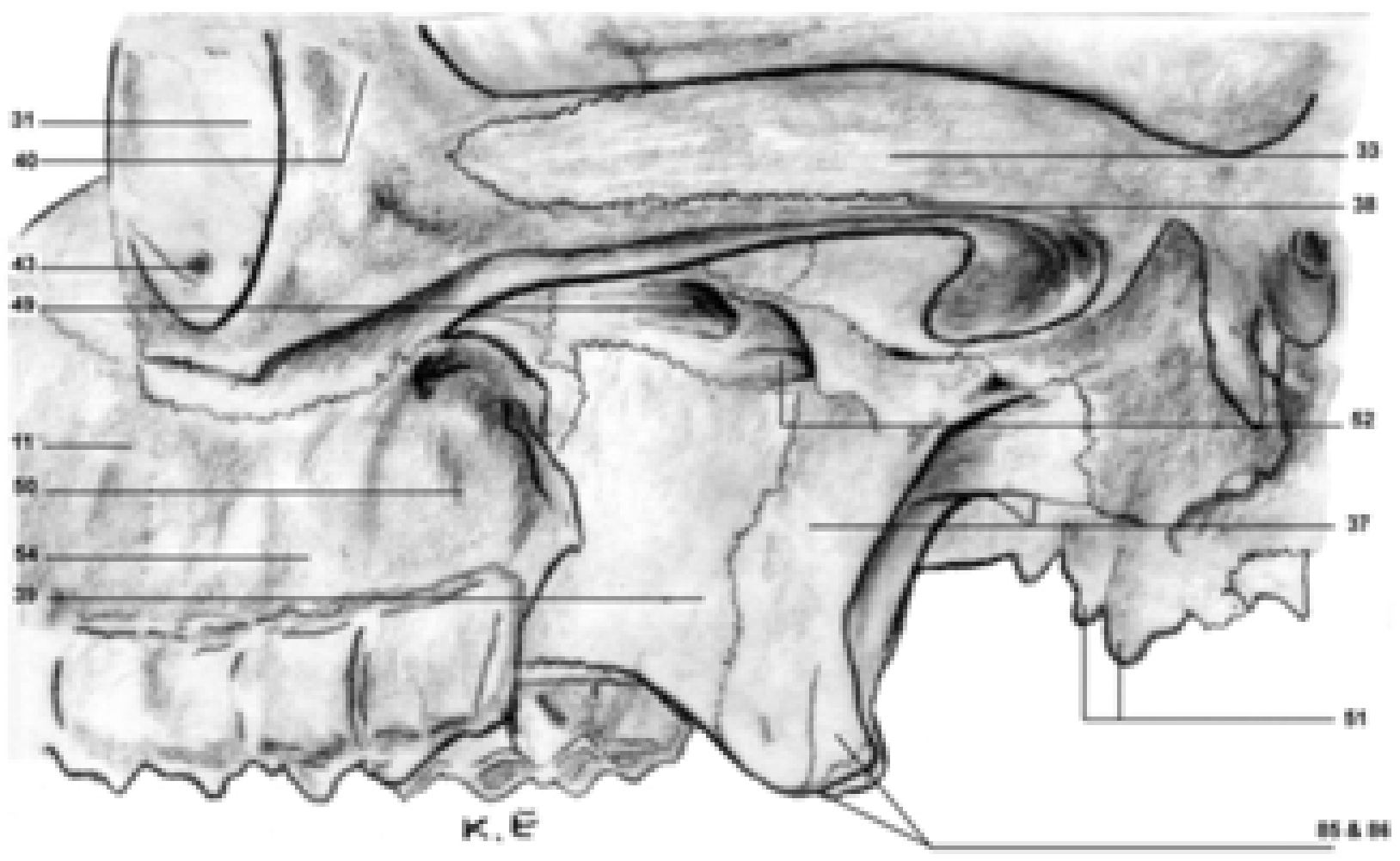

Figure 4. Ventro-lateral view of caudal part of adult female skull (See Appendix A for definitions). 

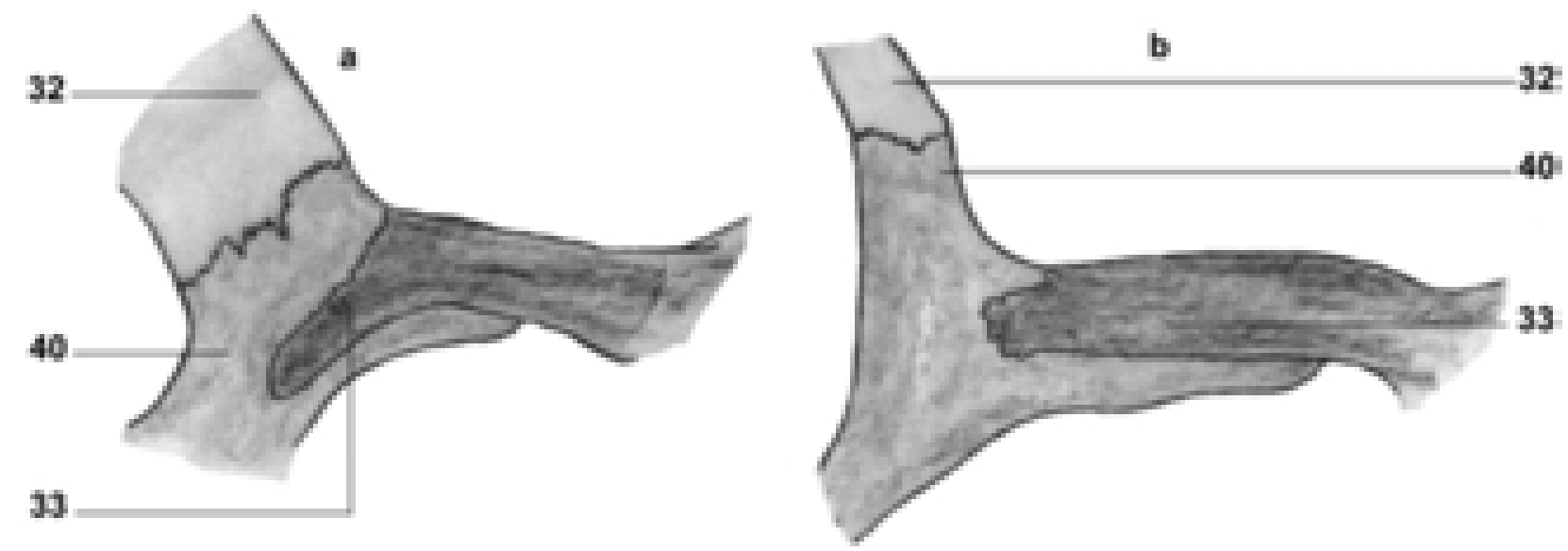

Figure 5. Age related development of temporal and zygomatic bones processes in zygomatic arch region. a: 2-years-old male; b: 9-years-old male (See Appendix A for definitions).

(Os presphenoidale) and sphenoid (Os basisphenoidale) bones, (2) the particular sphenoidal angle (Angulus sphenoidalis) of the parietal bone (Os parietale) and (3) the perpendicular part of palatine bone (Os palatinum, Lamina perpendicularis). Similar sphenoidal angle of parietal bone was also described by Lesbre (1903) in the Bactrian camel. In the dromedary camel, the sphenoidal angle of parietal bone is relatively well-developed compared to that reported in goat and sheep (GETTY, $1975 \mathrm{~b}$ ). The fovea trochlearis is located at $1.5 \mathrm{~cm}$ from the dorsal border of the orbit. Just behind and medially to the lacrimal foramen, appears the fovea of insertion of Musculus obliquus pentralis of the eye. Within this orbit region there are also several openings and foramina serving as pathways for blood vessels and nerves (See Figures 6 and 7 and Table 1). From our observations, it appears that these openings include: infratrochlear notch (Incissura infratrochlearis), the orbital opening of the supraorbital canal (Canalis supraorbitalis), lacrimal foramen (Foramen lacrimale), ethmoidal foramen (Foramen ethmoidale), optic foramen (Foramen opticum), rostral opening of the Canalis pterygoideus, orbitorotundum foramen (Foramen orbitorotundum). Moreover, in the pterygo-palatine fossa, it can be seen rostrally: the caudal palatine foramen (Foramen palatinum caudale), the spheno-palatine foramen (Foramen sphenopalatinum) which opens in the nasal cavity and the maxillary foramen (Foramen maxillare) which continues the infra-orbital canal (Canalis infraorbitalis) (Figures 6 and 7).

The optic foramen is particularly surrounded by bony specula, as it was also noticed by Chauveau (1879). According to Smuts and Bezuidenhout (1987), this specula is about $20 \mathrm{~mm}$ of length. The presence of similar specula was also reported by Lesbre (1903) in the Bactrian camel. The exploration of different skulls showed that the maxillary foramen is large in the young camel and becomes much larger in adult camels older than 7 years. Whereas in camels aged between 5 to 6 years, the entry of this foramen is almost closed by a well-developed bulla of the maxillary tuberosity (Tuber maxillae) which contains the $3^{\text {th }}$ molar tooth. The great expansion of this bulla is due to the growth of this tooth just before eruption from the maxillary alveoli. In addition to these foramina, we have identified in the pterygo-palatine fossa of the camel, two supplementary large foramens which have not been described before:

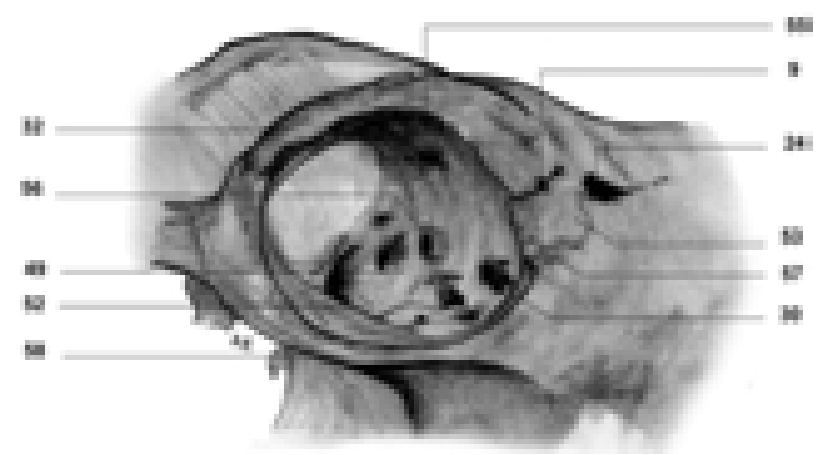

Figure 6. Lateral view of the orbit region of adult camel skull (See Appendix A for definitions).

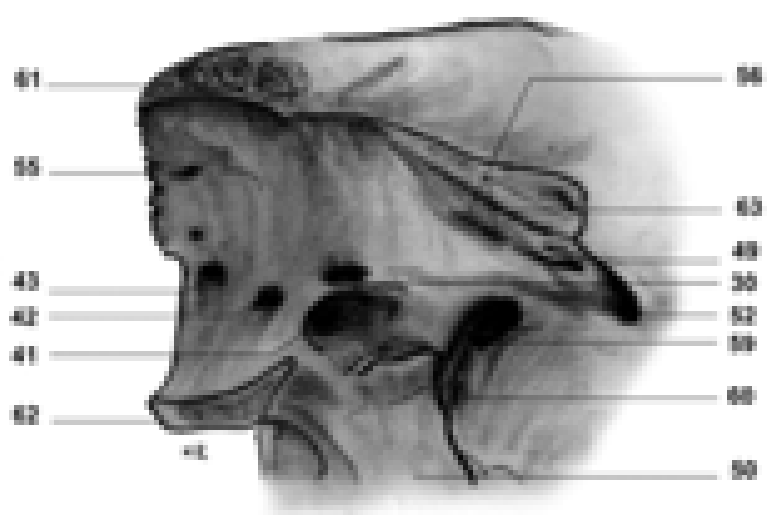

Figure 7. Caudal view of the orbit region of adult camel skull after removal of zygomatic process of frontal bone and orbital process of zygomatic bone (See Appendix A for definitions).

1)The first foramen lies dorsally to the maxillary foramen, at the junction of the maxillary, frontal, lacrimal and pterygoid bones. Like the spheno-palatine foramen, this hole is located laterally and opens into the nasal cavity but remains covered by a fibrous membrane in the living camel which may suggest the presence in the camel of two sphenopalatine foramina (Figure 7). 
Table 1. Blood vessels and nerves passing through camel skull foramina.

\begin{tabular}{|c|c|}
\hline Foramen & Structures passing through \\
\hline Supra-orbital foramina & Frontal vein (V. Frontalis). \\
\hline Foramen magnum & Spinal cord. \\
\hline Hypoglossal foramen & Hypoglossal nerve, condyloid artery (A. Condylaris) and the hypoglossal emissary vein. \\
\hline $\begin{array}{l}\text { Stylo-mastoid foramen } \\
\text { (Foramen stylomastoideum) }\end{array}$ & Facial nerve ( N. Facialis) and stylo-mastoid artery and vein (A. and V. Stylomastoidea). \\
\hline Retro-articulare foramina & Emissary vein of foramen retroarticulare ( V. Emmissaria Foraminis Retroarticularis). \\
\hline $\begin{array}{l}\text { Jugular foramen } \\
\text { (Foramen jugulare) }\end{array}$ & $\begin{array}{l}\text { Vagus nerve (N. Vagus), glosso-pharyngeal nerve ( } N \text {. Glossopharyngeus), a small branch } \\
\text { replacing the accessory nerve (N. Accessorius) and branch of the condylar artery } \\
\text { (A. Condylaris). }\end{array}$ \\
\hline $\begin{array}{l}\text { Lacerate foramen } \\
\text { (Foramen lacerum) }\end{array}$ & $\begin{array}{l}\text { Small vascular branches of the maxillary artery (A. Maxillaris) and branches of the } \\
\text { pterygoid nerves (N. Pterygoideus Lateralis / Medialis). }\end{array}$ \\
\hline $\begin{array}{l}\text { Foramen ovale } \\
\text { (Foramen ovale })\end{array}$ & $\begin{array}{l}\text { Mandibular nerve (N. Mandibularis), Middle meningeal artery (A. Meningea Media) } \\
\text { from maxillary artery, middle meningeal branch from the pterygoid branch and emissary } \\
\text { veins of foramen ovale. }\end{array}$ \\
\hline Carotid foramen & $\begin{array}{l}\text { Internal carotid artery ( } A \text {. Carotis Interna) and sympathetic fibers coming from the } \\
\text { cranial cervical ganglion (Ganglion Cervicale Craniale). }\end{array}$ \\
\hline Major palatine foramen & $\begin{array}{l}\text { Major palatine artery (A. Palatina Major), vein (V. Palatina Major) and nerve } \\
\text { (N. Palatinus Major). }\end{array}$ \\
\hline Caudal palatine foramen & $\begin{array}{l}\text { Major palatine, artery (A. Palatina Major), vein (V. Palatina Major) and nerve } \\
\text { (N. Palatinus Major). }\end{array}$ \\
\hline $\begin{array}{l}\text { Mastoid foramen } \\
\text { (Foramen mastoideum) }\end{array}$ & Posterior meningeal artery (A. Meningea Caudalis) and an emissary vein. \\
\hline $\begin{array}{l}\text { Infratrochlear notch } \\
\text { (Incissura infratrochlearis) }\end{array}$ & Inferior branch of the frontal nerve ( $N$. frontalis). \\
\hline $\begin{array}{l}\text { Ethmoidal foramen } \\
\text { (Foramen ethmoidale) }\end{array}$ & $\begin{array}{l}\text { Ethmoidal nerve (N. Ethmoidalis), External ethmoidal artery (A. Ethmoidalis Externa) } \\
\text { and vein ( V. Ethmoidalis Externa). }\end{array}$ \\
\hline $\begin{array}{l}\text { Optic foramen } \\
\text { (Foramen opticum) }\end{array}$ & $\begin{array}{l}\text { Optic nerve (Nervus Opticus), and internal ophthalmic artery }(A . \text { Ophthalmica } \\
\text { interna) and vein artery (V. Ophthalmica interna). }\end{array}$ \\
\hline $\begin{array}{l}\text { Medial spheno-palatine foramen } \\
\text { (Foramen sphenopalatinum) }\end{array}$ & $\begin{array}{l}\text { Spheno-palatine artery (A. Sphenopalatina), Spheno-palatine vein (V. Sphenopalatina) } \\
\text { and caudal nasal nerve (N. Nasalis Caudalis). }\end{array}$ \\
\hline Lateral spheno-palatine foramen & Closed in living camel by a fibrous membrane. \\
\hline $\begin{array}{l}\text { Orbito-rotundum foramen } \\
\text { (Foramen orbitorotundum) }\end{array}$ & $\begin{array}{l}\text { Oculomotor nerve (N. Oculomotorius), ophtalmic nerve (N. Ophthalmicus), } \\
\text { troclear nerve ( N. Trochlearis), abducent nerve ( N. Abducens), maxillary nerve } \\
\text { (N. Maxillaris), branches from maxillary artery which participate in formation of the } \\
\text { rete mirabile epidurale rostrale and emissary vein of orbitorotundum foramen. }\end{array}$ \\
\hline $\begin{array}{l}\text { Maxillary foramen } \\
\text { (Foramen maxillare) }\end{array}$ & $\begin{array}{l}\text { Infra-orbital artery (A. Infraorbitalis), infra-orbital vein ( } V \text {. Infraorbitalis) and nerve } \\
(N . \text { Infraorbitalis). }\end{array}$ \\
\hline $\begin{array}{l}\text { Infra-orbital foramen } \\
\text { (Foramen infraorbitale) }\end{array}$ & $\begin{array}{l}\text { Infra-orbital artery (A. Infraorbitalis), infra-orbital vein ( } V \text {. Infraorbitalis) and nerve } \\
\text { (N. Infraorbitalis). }\end{array}$ \\
\hline Mandibular foramen & $\begin{array}{l}\text { Inferior alveolar artery (A. Alveolaris Inferior), inferior alveolar vein } \\
\text { (V. Alveolaris inferior) and inferior alveolar nerve ( N. Alveolaris Inferior). }\end{array}$ \\
\hline Rostral mental foramen & $\begin{array}{l}\text { Ramus mentalis rostralis of the inferior alveolar artery (A. Alveolaris Inferior), ramus } \\
\text { mentalis rostralis of the inferior alveolar vein ( V. Alveolaris Inferior }) \text { and mentalis } \\
\text { rostralis branche of inferior alveolar nerve }(N \text {. Alveolaris Inferior }) \text {. }\end{array}$ \\
\hline Caudal mental foramen & $\begin{array}{l}\text { Ramus mentalis caudalis of the inferior alveolar artery (A. Alveolaris Inferior), ramus } \\
\text { mentalis caudalis of the inferior alveolar vein (V. Alveolaris Inferior }) \text { and mentalis } \\
\text { caudalis branche of inferior alveolar nerve }(N \text {. Alveolaris inferior }) \text {. }\end{array}$ \\
\hline
\end{tabular}

2)The second foramen is localized behind the lacrimal foramen, just in front of the maxillary foramen. It leads to a duct which opens into the maxillary sinus (Sinus maxillaris). This opening was than considered as the accessory maxillary foramen (Figure 7). The insertion of the ventral oblique muscle of the eye (M. obliquus ventralis) in the corresponding fossa (Fossa m. oblique ventralis) extends deeply within this foramen.
Facial region: This region is characterized by the absence of both the facial crest (Crista facialis) and the facial tubercle (Tuber faciale) and the existence of a deep depression at the medio-rostral side of each orbit (Figures 1 and 2). At the dorso-lateral edge of this depression, we found a large hole, which was not previously well described. This opening is located at the junction of the lacrimal, frontal, nasal and maxillary bones (Figures 1, 2, 6 and 8 ) and it opens also into the nasal 
cavity. Chauveau (1879) has previously revealed the existence in camel of an orbital or nasal opening into and near the dorsal concha. The presence of a similar hole, between frontal, nasal and maxillary bones, has been reported in Bactrian camel. Indeed, Lesbre (1903) described the existence of a large fontanel at this level. This later appears as membranous gaps between the incompletely formed cranial bones of a fetus. The author reported that this foramen is usually absent in the dromedary camel. However, in the majority of the skulls examined, we noticed the presence of such fontanel, while in well-aged ones of which the adjacent bones are completely formed, and therefore the fontanel is closed, we found instead a thick hole of 1 to $2 \mathrm{~mm}$. Moreover, this hole has been described in lama as a fontanel (LESBRE, 1903) or as lacrimal foramen (GALOTTA and GALOTTA, 1994) and reported also in goat by Barone (1976) and Shawulu, Kwari and Olopade (2011). Apparently, this foramen is equivalent to numerous openings seen in this region of the rabbit skull and resulting from an ossification defect of the maxillary bone (BARONE, 1976). In living camel, this hole is filled by a fibrous membrane. More rostrally and ventrally, as it was described in the Bactrian camel (LESBRE, 1903), appears a large infra-orbital foramen (Foramen infraorbitale) just above the $3 \mathrm{rd}$ premolar tooth.

The observations of the maxillary bone of the camel show that this latter presents a nasal process (Figure 8a) which expands differently according to the age. In fact, this process is flunked caudally by the junction of the nasal and the incisive bones in young animals (Figure 8a). As the animal is getting older, the process becomes longer and larger and moves rostro-dorsally (Figure 8b) reaching its maximal length in more aged camels in which it is intercalated between nasal and incisive bones (Figure 8c). Therefore, the maxillary bone is incorporated in the rostral opening of the nose in the camel. Yahaya, Olopade, Kwari et al. (2012a) reported that in $20 \%$ of adult camels, there is a definite incisivo-naso-maxillary junction while in the other $80 \%$, a naso-maxillo-incisive notch created by an interval of varying distances of the maxilla is seen between the incisive and the nasal bones. These differences are, as we reported in this work, a consequence of the age related development of the nasal process of the maxillary bone. In the Bactrian camel, Lesbre (1903) didn't report such age related variations.

Rostrally, the incisive bone shows a unique incisor tooth, the third one. According to the description of Chauveau (1879), the superior teeth of the camel include: one incisor, two like- shaped canine and five molar teeth while in fact the real upper teeth formula consist of a unique incisor, a large canine, the first premolar tooth which has a canine shaped and is totally disconnected from the other premolar and molar teeth. This first premolar tooth interrupts the inter-alveolar margin (Margo interalveolaris) between the large canine tooth and the $2^{\text {nd }}$ premolar tooth (Figure 2). Behind to the $2^{\text {nd }}$ premolar tooth there is a $3^{\text {rd }}$ premolar and three molar teeth. Similar upper teeth formula has been described by Lesbre (1903) and Smuts and Bezuidenhout (1987).

\subsubsection{Ventral view (Figure 9)}

Cranium region: This region corresponds to the caudal part of skull and shows the margins of the foramen magnum (Foramen magnum) which is delimited by the two large occipital condyles (Condylus occipitalis). These condyles are close to the median line. Furthermore, Lesbre (1903) reported the presence in the Bactrian camel of a third occipital condyle.
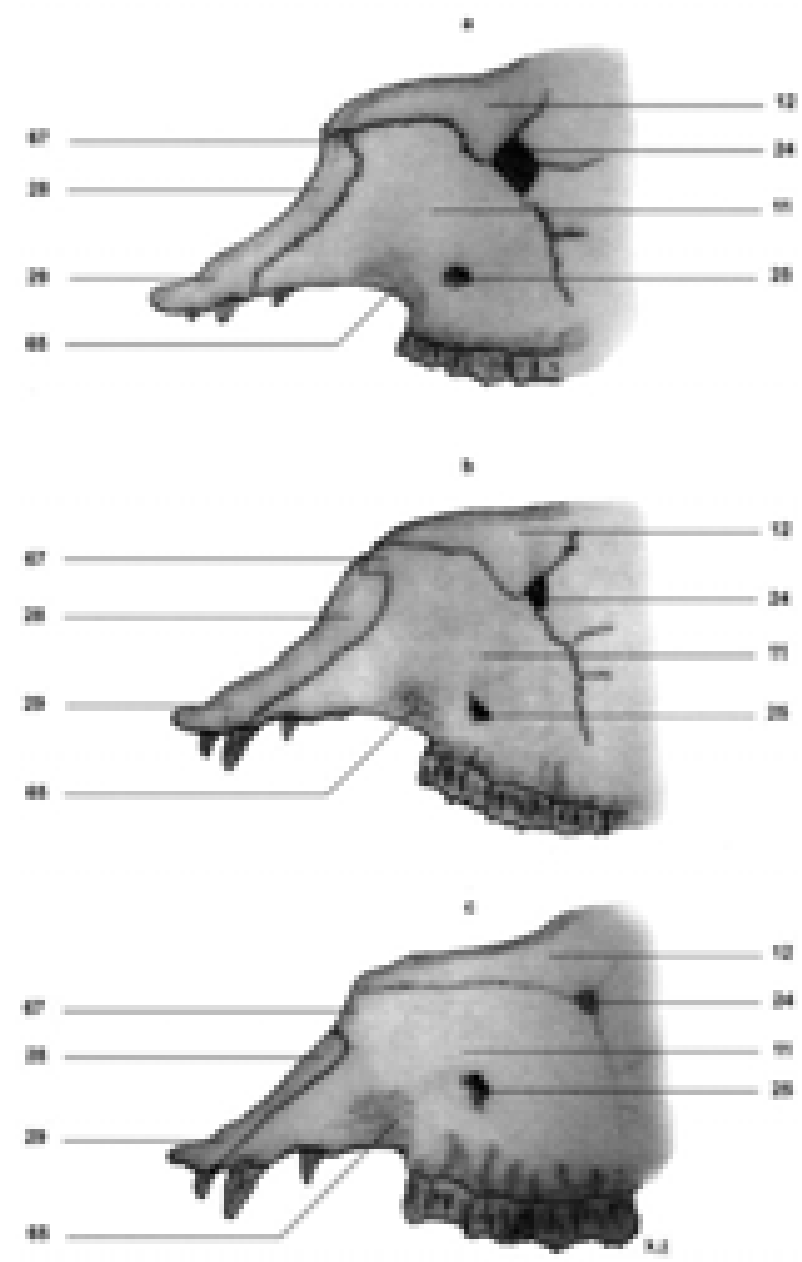

Figure 8. Age related development of nasal process of the maxilla. a: 2,5-old male; b: 5-years-old male; c: 9-years-old male (See Appendix A for definitions).

Medially to the ventral condylar fossa (Fossa condylaris ventralis) opens the hypoglossal canal (Canalis n. hypoglossi) (Figures 9 and 10). In contrast, Müller (1962) described the existence of two hypoglossal canals. It is quite evident that one of these corresponds to an accessory foramen we observed in $80 \%$ of the skull examined in this work. In addition, the opening of the condylar canal (Canalis condylaris) is also observed dorsally to this later.

The muscular tubercle (Tuberculum musculare) of the basilar part (Pars basilaris) of the occipital bone is more developed in the young camel while it becomes erased in the adult ones. Such tiny tubercles were also described in the Bactrian camel (LESBRE, 1903). Between the two tubercles of the young camel lies an important median groove.

The jugular process (Processus jugularis) of the occipital bone is short and fuses to the vaginal process of the temporal bone (Figure 9). In the lama, this fusion is not achieved and the well-developed jugular process extends ventrally beyond the ventral edge of the occipital condyle (GALOTTA and GALOTTA, 1994). Moreover, the tympanic bulla is not well developed in camel and does not form a real bulla as described by Barone (1976) in other domestic mammals especially in carnivores, rabbit, swine and cattle. The vaginal process 


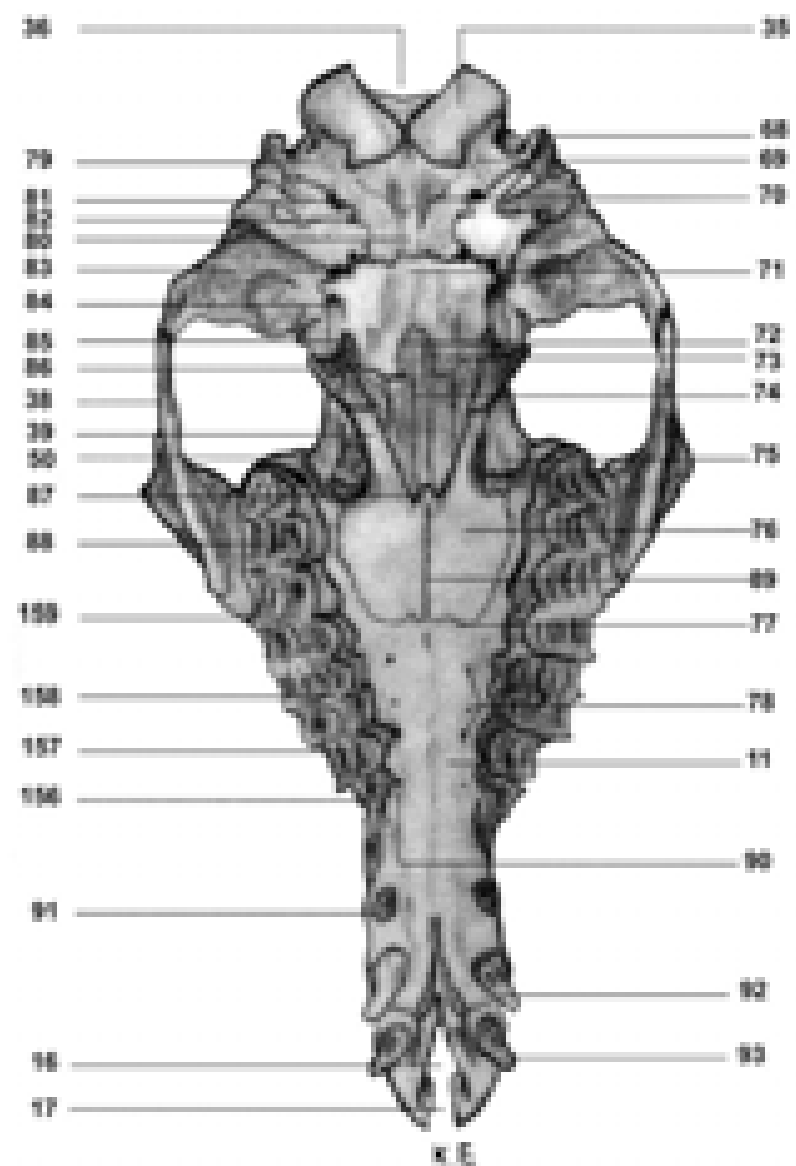

Figure 9. Ventral view of adult male skull (See Appendix A for definitions).

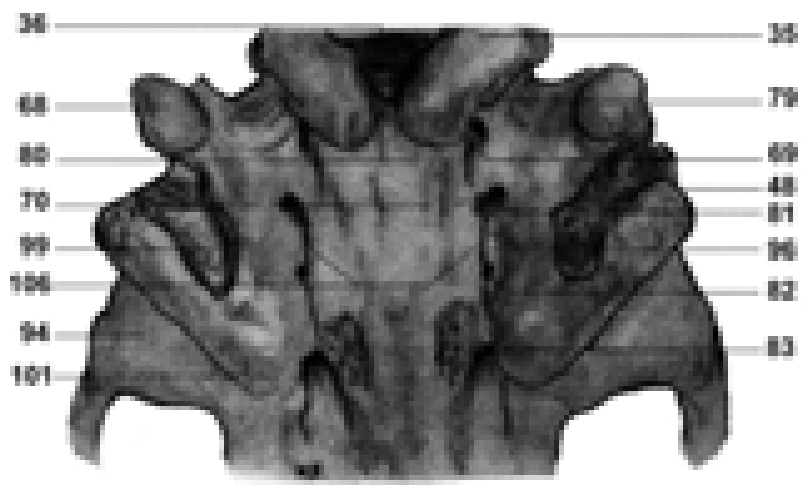

Figure 10. Details of caudal part of ventral view of adult female skull (See Appendix A for definitions).

encloses a deep fossa which is rostrally surrounded by the tympanic bulla and opens ventrally (Figure 10). Deeply in this fossa, lies the styloid process (Processus styloideus) which ensures the junction to the Tympanobyoideum (Figure 11). The elevated edges of this fossa seem to reduce the hyoid apparatus movements and therefore probably prevent, in living animal, excessive movements of the pharynx and the larynx.

The mastoid process of the temporal bone is related rostrally to the external acoustic meatus and shows ventro-medially the opening of the stylo-mastoid foramen (Foramen stylomastoideum) which is usually surrounded by 2 to 4 accessory foramina.

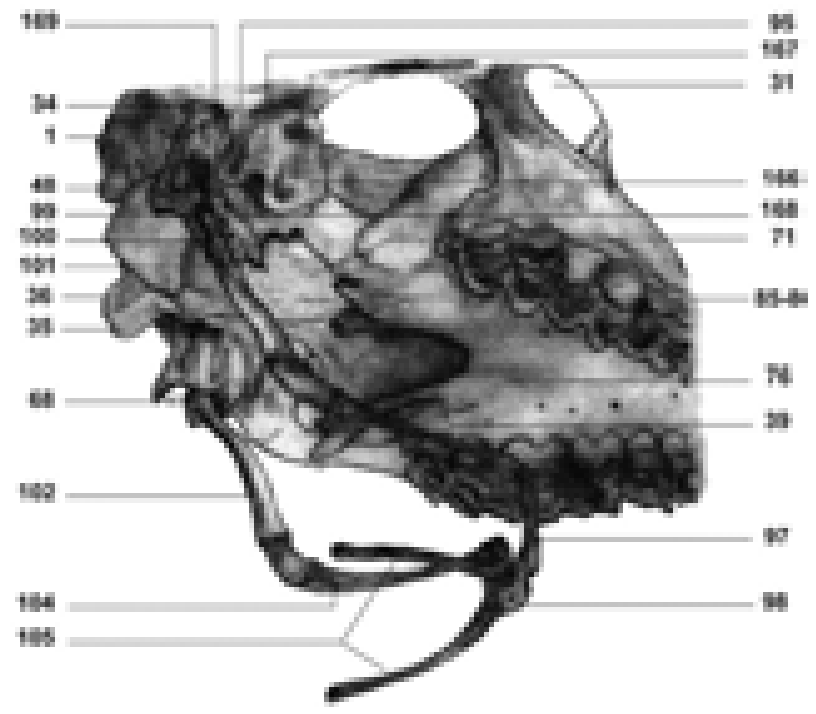

Figure 11. Ventro-caudal view of adult female skull showing position of hyoid apparatus (See Appendix A for definitions).

The tympanic portion of the temporal bone fuses with the basi-sphenoid bone (Figure 10) and forms the tympano-occipital fissura (Fissura tympanooccipitalis). This later is usually larger in young camel's skulls. This fissure is intercalated between the jugular foramen (Foramen jugulare) and the external opening of the carotid canal (Canalis caroticus) (Figure 10). Rostrally, appears the opening of the lacerate foramen (Foramen lacerum) which extends as a groove along the surface of the basi-sphenoid bone reaching the pterygoid canal (Canalis pterygoideus). A quit similar disposition of this lacerate foramen has been also described in swine (GETTY, 1975a) and lama (GALOTTA and GALOTTA, 1994). Accordingly, in this species, it opens between the basi-sphenoid, the occipital and the temporal bones. Lesbre (1903) has early reported the existence of 2 lacerate foramina: a rostral lacerate foramen which corresponds to the main lacertae foramen as described in the present work and a caudal lacerate foramen consisting of 3 holes. With a careful investigation of different vascular and nervous components having access into these formina, we found that the caudal lacerate foramen described by Lesbre (1903) consists in fact of two holes: the carotid foramen and the jugular foramen. Similarly, Smuts and Bezuidenhout (1987) have shown the existence of a unique lacerate foramen beside the carotid and jugular foramina. However, according to these authors, the opening of the carotid canal and lacerate foramen are merged. Using fresh injected head and after a careful dissection, we were able to elucidate that the related opening of the carotid canal is in fact covered by fibro-cartilaginous layer along the pterygoid fissure (Incisura pterygoidea) and that it gives access to only small branches of the maxillary artery (Arteria maxillaris) and branches of the pterygoid nerves and seemingly it corresponds to the lacerate foramen; whereas the internal carotid artery (Arteria carotid interna) goes through another distinct foramen located caudally to the jugular foramen on the tympano-occipital fissure which, in fact, constitutes the proper external opening of the carotid canal (Figure 12). From the intra-cranium outlet of this canal, the carotid artery participates to the formation of the caudal rete mirabile. On the other hand, the jugular foramen gives access 

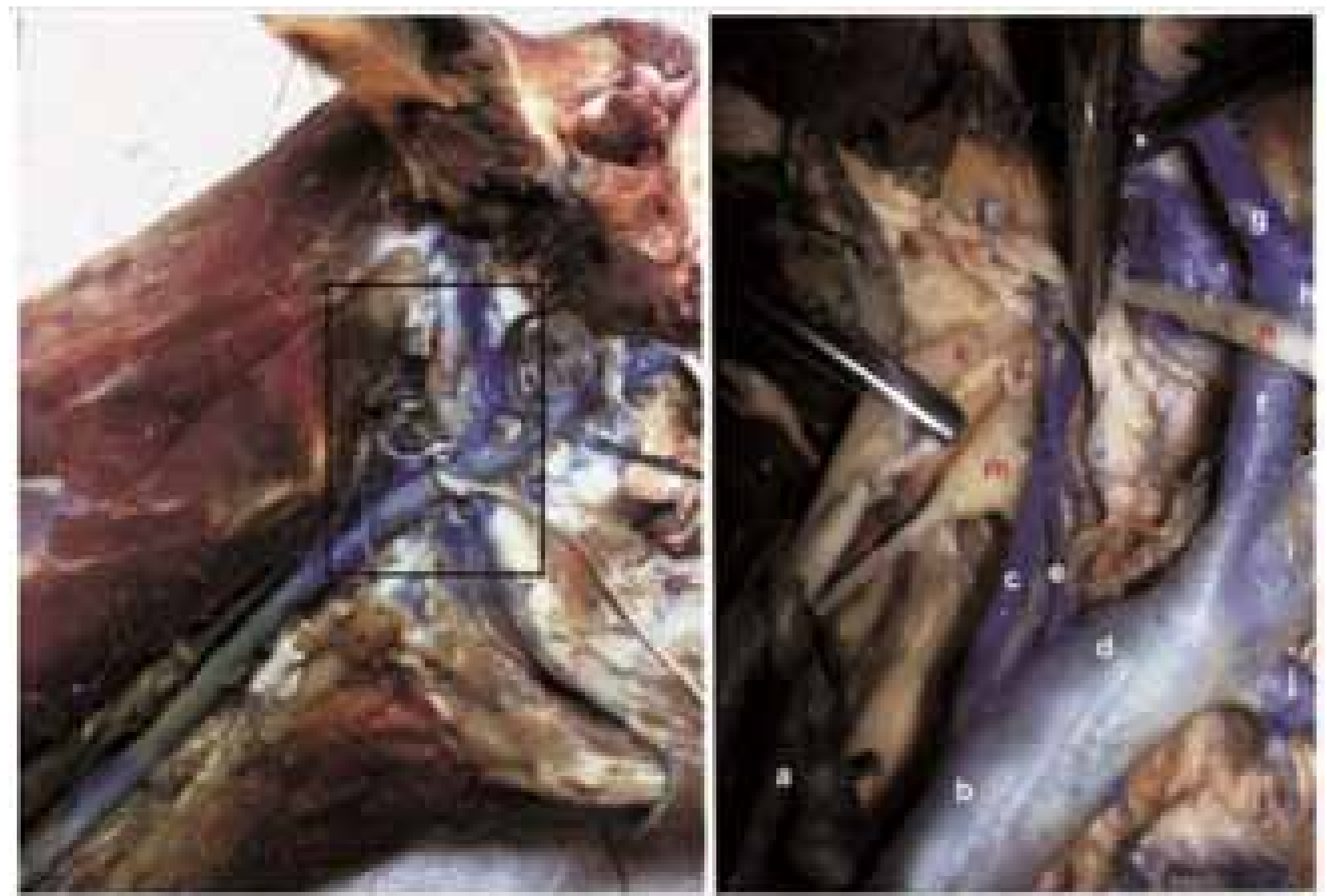

Figure 12. Results of dissection showing the internal carotid artery going through the carotid foramen (See Appendix A for definitions).

to $\mathrm{IX}^{\text {th }}$ and $\mathrm{X}^{\text {th }}$ cranial nerves (The Glosso-pharyngeal and the Vagus nerves), a tiny branch representing the accessory nerve (XI) and a branch of the condylar artery serving the meninges (Table 1). In the Lama glama, Howell and Straus Junior (1934) also described the existence of a branch of accessory nerve, emerging near the jugular foramen. The pathway and distribution of the tiny branch of the accessory nerve in camelids has been largely discussed by Müller (1962).

The ventral view of the cranium region shows also many other foramina. Rostrally and laterally to the lacerate foramen, occurs the foramen ovale (Foramen ovale) serving as a pathway for several vessels and nerves (see Table 1). Moreover, 3 or 4 small holes are observed laterally to the lacerate foramen. These holes correspond to the opening of the Canalis musculotubarius which is the bony canal of the auditory tube (Tuba auditiva) connected to the middle ear. Also, in the ventral view, appear the rostral opening of the Canalis pterygoideus and the medial retro-articular foramen as described above. Medio-caudally to this later occurs the opening of the Canaliculus chordae tympani.

The articular surface of the temporo-mandibular joint includes a rostral articular tubercle (Tuberculum articulare), a glenoidal cavity and retro-articular process. This later is particularly developed in the dromedary and the Bactrian camel (LESBRE, 1903) compared to the other domestic mammals.

The basi-sphenoid body (Os basisphenoidale, Corpus) is horizontally positioned and extends vertically on both sides by a pterygoid process (Processus pterygoideus). This later is particularly developed in the camel that it joins the perpendicular part of the palatine bone. The extremity of this process forms a true lateral hamulus which delimits with the pterygoid hamulus of the pterygoid bone (Os pterygoideum, Hamulus pterygoideus), a deep pterygoid fossa (Fossa pterygoidea): Figures 11 and 13. A similar deep fossa exists also in the Bactrian camel (LESBRE, 1903), in the lama (GALOTTA and GALOTTA, 1994) and in swine (GETTY 1975a; BARONE, 1976).

Intermediate region: This region corresponds to the posterior opening of the nasal cavities (Choanae) into the naso-pharynx. In the camel, the opening of the choanae is not bordered caudally and is divided into two compartments by the vomer bone. This later expands more caudally and presented at its end a particular shape (Figure 13). This includes two processes, a large and thin one, which cover the basi-sphenoid body without fusing to it.

As reported above, the age related development of the maxillary tuberosity affects the general conformation of adjacent structures: such as the opening of maxillary foramen and the pterygo-palatine fossa. We have observed that the large changes seen in the maxillary tuberosity are the result of the development and eruption of the $3^{\text {th }}$ molar tooth. This eruption occurs between 5 and 6 years of age. Thus, young camels progressing in age have a developed maxillary tuberosity reaching a maximum at 5-6 years old. At this age the tuberosity is very extensive showing a maxillary bulla which reduces the pterygo-palatine fossa and other related structures. The progressive eruption of this $3^{\text {rd }}$ molar tooth leads to an enlargement of the ventral perforation of the maxillary bone (Figure 14) and to the disappearance of this bulla thereafter.

Facial region: It presents an extension of the choanae and is formed by (1) the horizontal part (Lamina horizontalis) of the palatine bone; $(2)$ the palatine (Processus palatinus) and 


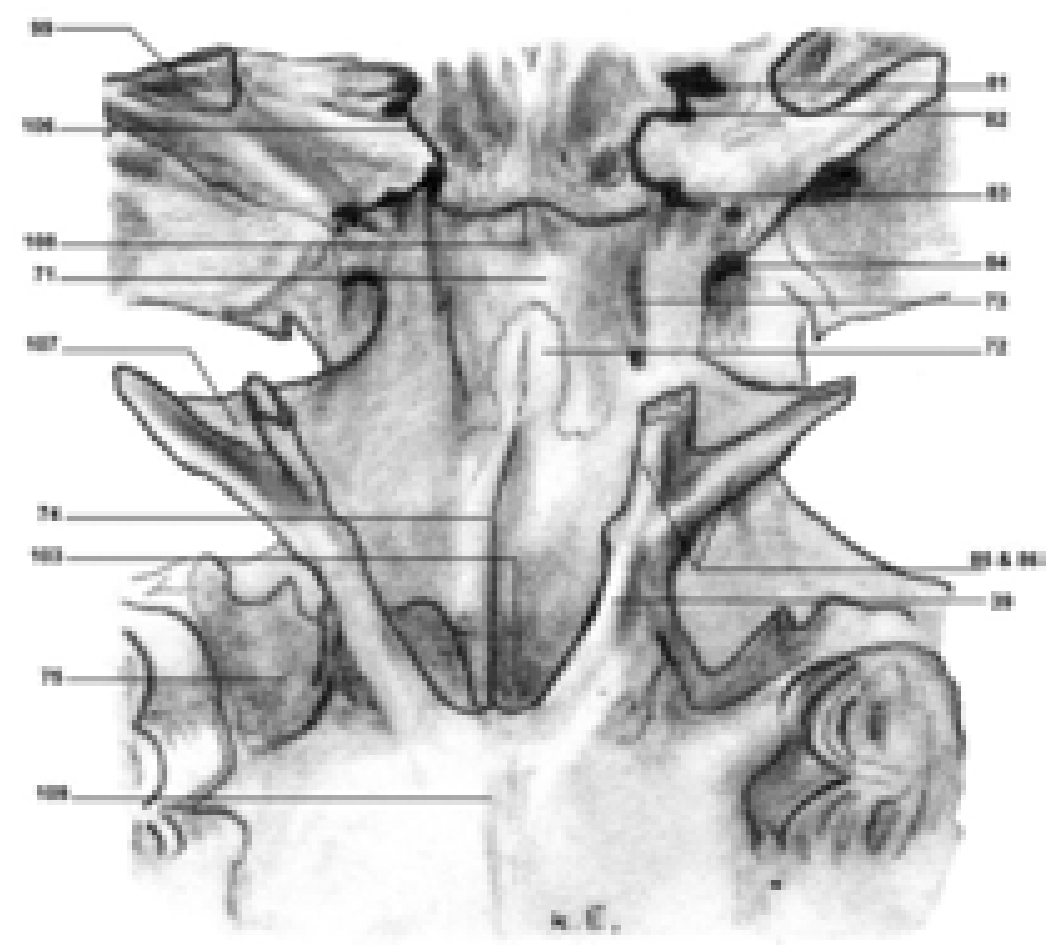

Figure 13. Details of intermediate region of the ventral view of adult male skull (See Appendix A for definitions).
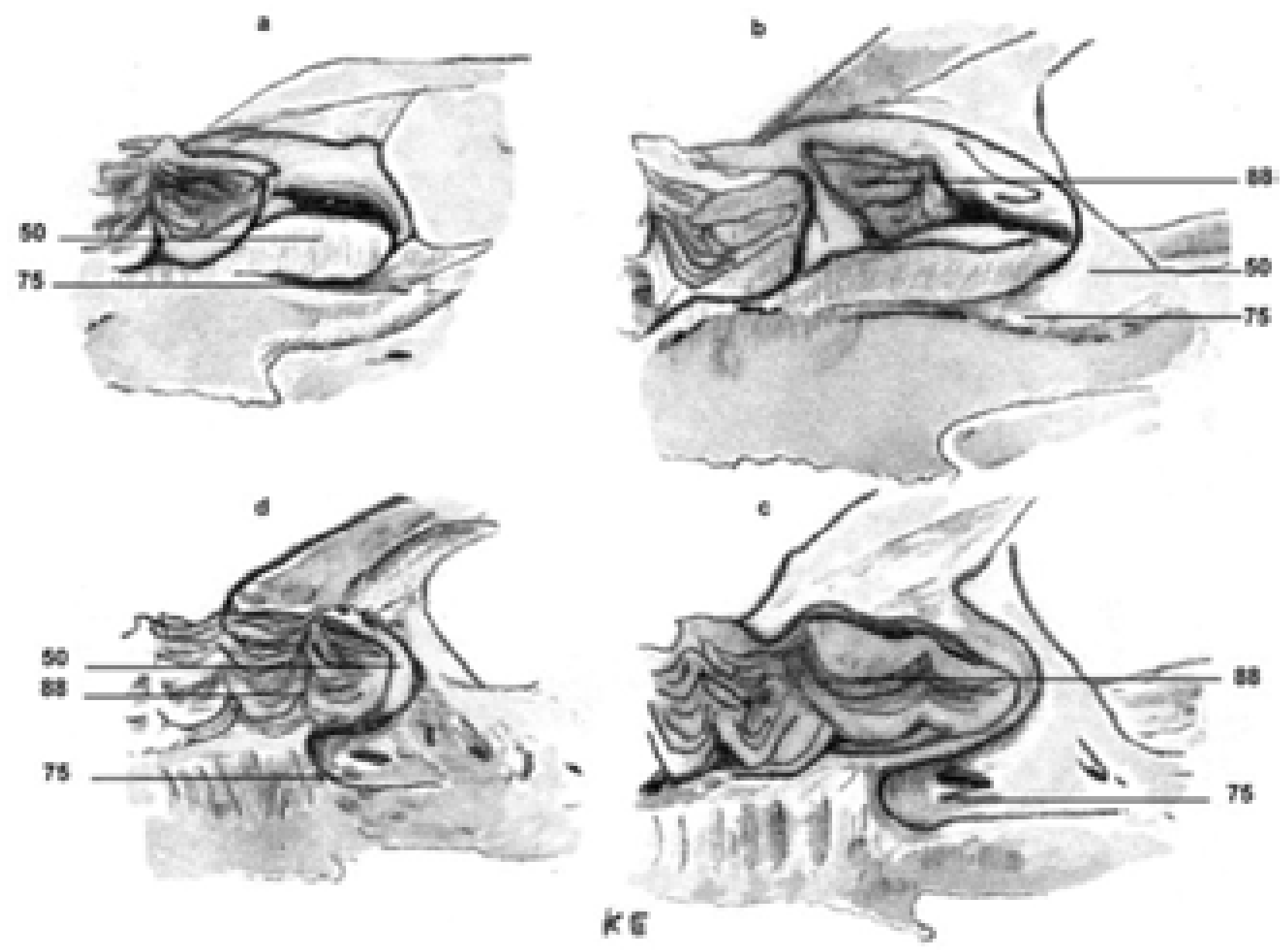

Figure 14. Age related development of the maxillary tuberosity resulting from the development and eruption of the $3^{\text {th }}$ molar tooth. a: 4-years-old male; b: 5-years-old male; c: 6-years-old male; d: 9-years-old male (See Appendix A for definitions). 
(3) the alveolar (Processus alveolaris) processes of the maxillary bone; and (4) the incisive bone. The median palatine suture (Sutura palatina mediana) is formed at the lines of fusion of the two palatine bones and that of the two maxillae bones. This suture extends rostrally by the inter-incisive suture (Sutura interincisiva). The latter suture is bordered at each side by a palatine fissura (Fissura palatina) and ends rostrally in a unique inter-incisive fissura. The fusion of palatine bone and the palatine process of the maxillary bone forms a transverse palatine suture (Sutura palatine transversa). Behind this suture, at the level of the $2^{\text {nd }}$ or $3^{\text {rd }}$ premolar tooth, the major palatine foramen (Foramen palatinum majus) opens into the palatine process of the maxillary bone by a main hole while the usual palatine groove (Sulcus palatinus) observed in most domestic animals especially in horse, small ruminant, swine and $\operatorname{dog}$ (SISSON and GROSSMAN, 1953) is lacking in the camel. Other accessory palatine holes are aligned and open at the level of the other molar teeth.

\subsubsection{Caudal view (Figure 15)}

This part is semi-circular in shape and is occupied by the occipital bone. It shows a deep foramen magnum surrounded by the two large occipital condyles and limited dorsally by the nuchal tubercle (Tuberculum nuchale) (Figure 15). In a

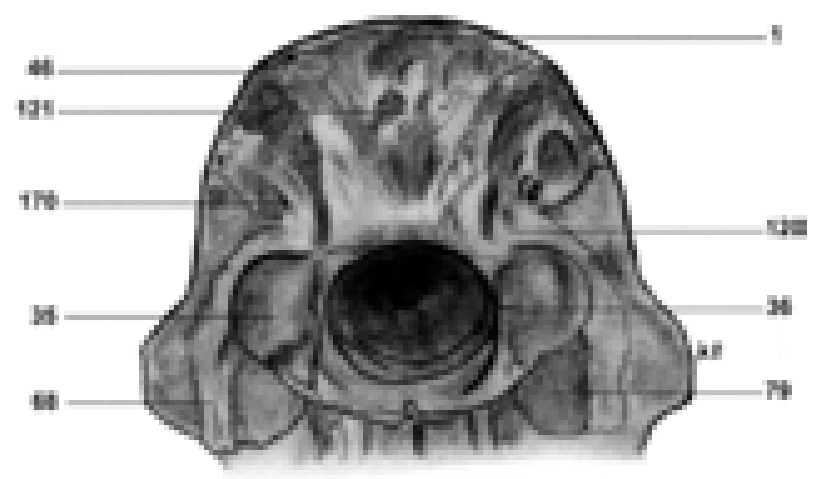

Figure 15. Caudal view of adult female skull (See Appendix A for definitions). previous study carried out by Yahaya, Olopade and Kwari (2013) on different camel skulls obtained from northern Nigeria, the authors revealed that this foramen magnum shows morphological variations, especially in its dorsal border. Indeed, a curved margin, a small ventrally directed median protrusion or a dorsal notch were observed. In our study, such structures were not observed. Dorsally to this caudal region, there is a transversal large external occipital protuberance surrounding the caudal structures. Each occipital condyle shows (1) Ventro-laterally a ventral condylar fossa (Fossa condylaris ventralis) containing the opening of condylar canal (Canalis condylaris) and (2) dorsally a deep dorsal condylar fossa (Fossa condylaris dorsalis) in which a vascular foramen, Foramen mastoideum, opens just near to the occipito-temporal suture. The dorsal fossa is limited dorsally by the nuchal crest and shows a mastoid crest. The jugular process is not well expanded and fuses to both the mastoid process and the well-developed retro-tympanic process.

\subsubsection{Rostral view}

The rostral region of the camel skull is quite narrow. It includes the incisive bone laying just below the rostral opening of the nasal cavity. At this view, the incisive bone shows (1) a body part (Corpus ossis incisive) presenting a labial surface and a palatine surface, (2) a nasal process reaching the dorsal part of the nasal region and (3) an alveolar process containing a unique alveolar dental of the third incisor. This process is arch-shaped, flattened dorso-ventrally and interrupted by the inter-incisive fissura.

\subsubsection{Internal view (Figure 16)}

The internal view of the skull shows a cranium cavity and a nasal cavity with the related para-nasal sinuses annexed to it.

The cranium cavity (Cavum cranii) extends from the foramen magnum to the ethmoidal bone (Os ethmoidale). It is partly divided by the Tentorium cerebelli osseum (Figures 16 and 17) into two cavities: rostral and caudal. This Tentorium cerebelli osseum is formed by (1) a rounded but slightly elevated internal occipital protuberance, (2) by a lateral Processus tentoricus formed by parietal and temporal bones and (3) by a sharp crest: the Crista partis

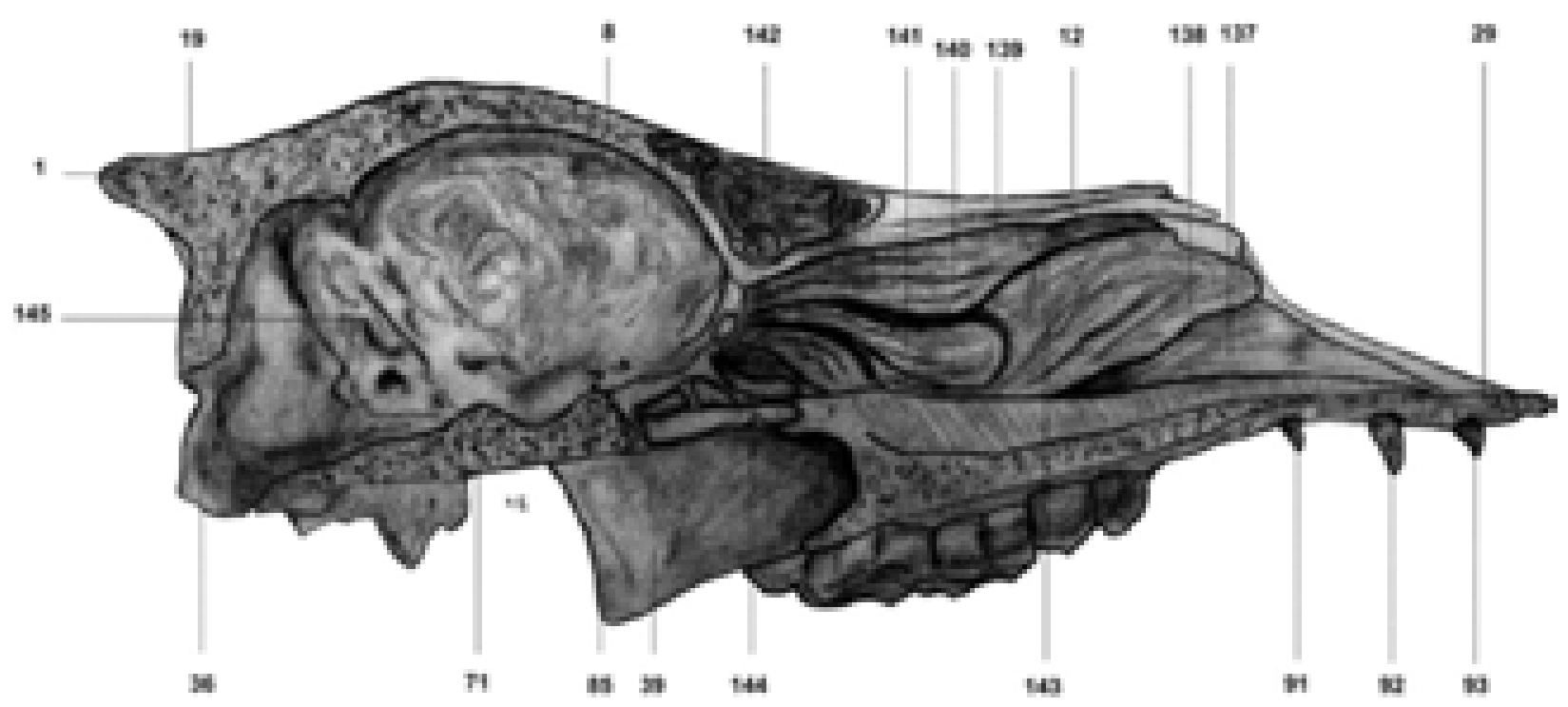

Figure 16. Internal view of adult male skull, median section (See Appendix A for definitions). 
petrosae extending ventrally to the basal part of the cranium cavity. The roof of the caudal cavity shows marked imprints made by Vermis cerebelli, the Impressio vermialis. Whereas, in the rostral cavity, the major imprints of the cerebral gyri form the Impressiones digitatae. The roof of the cranium shows in its rostral cavity a developed internal sagittal crest: Crista sagittalis interna; while the rostral wall is excavated into two deep ethmoidal fossa (Fossa ethmoidales), separated by a crest of the ethmoidal bone: Crista galli which extended to the internal lamina of the frontal bone. The internal surface of the cranium base (Basis cranii interna) is divided by two transversal elevated structures into three fossa: a long rostral cranium fossa (Fossa cranii rostralis), a developed median fossa (Fossa cranii media) and caudal fossa (Fossa cranii caudalis). The median fossa which is taken place on the basi-sphenoid, is excavated by the Sella turcica (Figure 17) which includes (1) a deep Fossa bypophysialis, (2) a prominent Dorsum sellae which is in the back (3) a particular Processus clinoideus caudalis. The Fossa hypophysialis shows in the camel the opening of two canals: Canalis craniopharyngeus. The internal opening of camel cranium foramina presents also some peculiarities regarding its position and shape (Figure 18).

The nasal cavity (Cavum nasi) extends from its rostral opening to the choanae (Figure 16). It contains three conchae: (1) the dorsal one ends with a thin process (2) The ventral or ventro-rostral concha is well developed, and (3) a middle nasal concha which is ventro-caudal and corresponds to a well-developed turbinates of the ethmoidal bone. Unlike Chauveau (1879) who considered the anatomical arrangement of camel's conchae as similar to those in other domestic mammals, we revealed in the present work some important differences of both disposition and shape of these conchae. Indeed, the ethmoid bone forms another well-developed turbinate located dorso and medially to the middle concha. This later was considered in the Bactrian camel as the $4^{\text {th }}$ nasal concha (LESBRE, 1903). We have also shown that the ventral concha consists of two thin bony plates, medial and lateral turbinates which rostrally change direction and became dorsally and ventrally. Unlike the ventral, the dorsal and middle conchae present each a sinus compartment. This result was also shown by using computed tomography (ALSAFY, EL-GENDY and ABUMANDOUR, 2014). The nasal cavity of the camel shows also four nasal meatus: dorsal, ventral, middle and a common one. The middle meatus is itself divided caudally into a dorsal and ventral meatus bordering the middle nasal concha. The ventral meatus is large that could be used for naso-gastric intubation. The common meatus is located medially to the others just against the nasal septum (Septum nasi osseum). Its ventral part is formed by a semi-canal shaped vomeral groove (Sulcus vomeris). Similar conformation of conchae has been reported in the Bactrian camel (LESBRE, 1903) and in the lama (GALOTTA and GALOTTA, 1994) in which the ventral one seems to be less developed than in the camel.

Concerning the para-nasal sinuses, there are five pairs in the camel: Sinus frontalis, Sinus maxillaris, Sinus lacrymalis, Sinus ethmoidalis and Sinus sphenoidalis. The sinus frontalis is relatively quit narrow and is divided into several compartments. Tomographic scans show that there is six large compartments of this sinus; two caudal, two lateral, and two rostral surrounding eight small compartments (ALSAFY, EL-GENDY and ABUMANDOUR, 2014). The sinus maxillarie is separated from the lachrymal sinus (Sinus lacrimalis) by the nasolacrimal

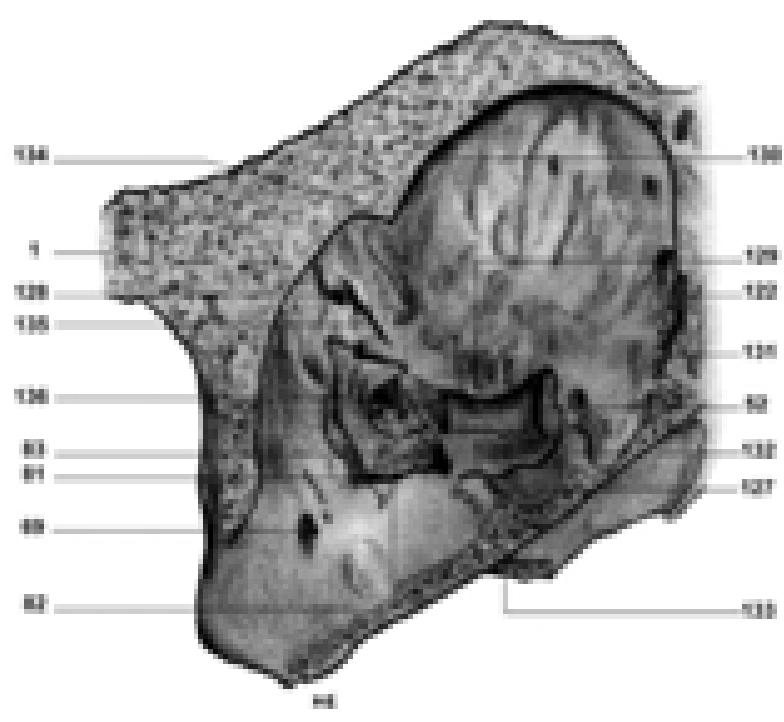

Figure 17. Caudo-lateral view of half cranium cavity of adult male skull (See Appendix A for definitions).

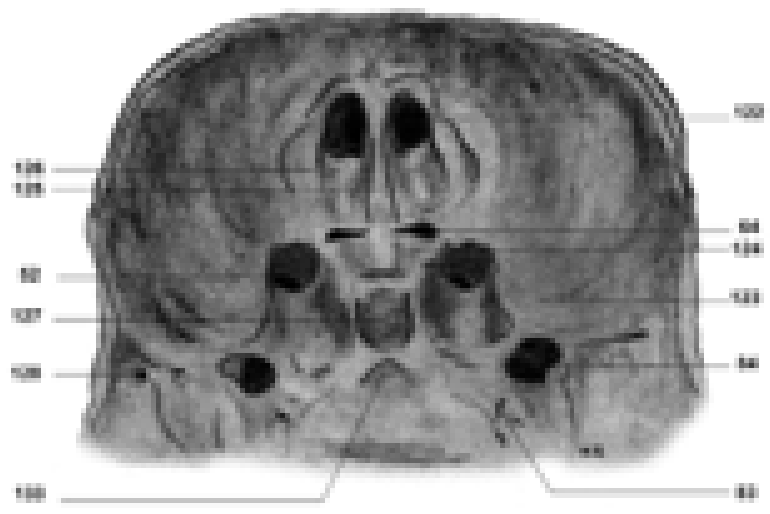

Figure 18. Caudal view of the rostral part of cranium cavity of adult male skull. Calvarium is removed (See Appendix A for definitions).

duct (Ductus nasolacrimalis). According to Lesbre (1903), this maxillaries sinus is missing in the Bactrian camel. The sinus lacrimalis opens together with the sinus maxillaris into the nasal cavity. The sinus ethmoidalis is located in the depth of the ethmoidal bone, while the sphenoidal sinus is small and located caudally just below the ventral turbinate of the ethmoidal bone.

\subsection{Mandible}

The mandible presents two joined flat parts (Figure 19): the body (Corpus mandibulae) and the ramus (Ramus mandibulae). The incisive part of the body fuses early to its opposite to become, after birth, the mandibular symphysis. This later is particularly extended caudally in the camel toward the $2^{\text {nd }}$ premolar tooth. The symphysis length is about $13.2 \pm 0.8 \mathrm{~cm}$ of a total length of the mandible of $38 \pm 1.6 \mathrm{~cm}$. Thus, it constitutes the longest symphysis in all domestic mammals. A long mandibular symphysis of 10 to $12 \mathrm{~cm}$ of length was also reported in the Bactrian camel (LESBRE, 1903). The incisive part exhibits on each side the implantation of three incisors teeth and one canine. As, in the upper jaw, the Margo interalveolaris is interrupted by a canine like shape 


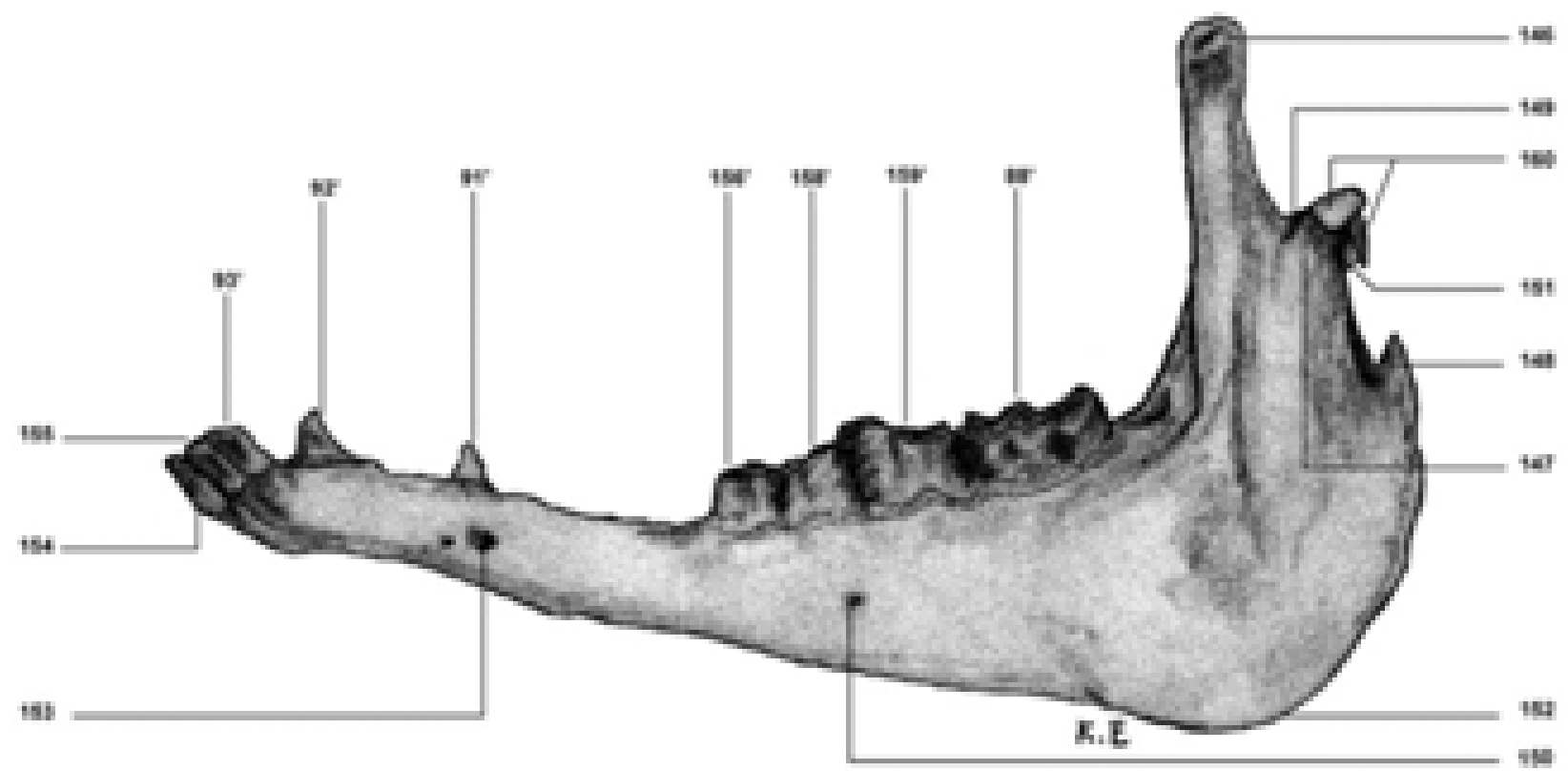

Figure 19. Lateral view of left mandible of adult female (See Appendix A for definitions).

first premolar tooth. The molar part of the mandibular body is relatively brief in the camel compared to other ungulates. It is occupied by the alveoli of the $2^{\text {nd }}$ premolar and the three molar teeth. The camel lower jaw dental formula as reported by some authors seems to be erroneous. The controversy concerns mainly the canine and the first premolar teeth. Indeed, Chaurasia, Tiwari, Pandey et al. (2010) described the presence of two canines on each side (I 3, C 2, PM 3, M 2 or 3): a rostral one close the third incisor and a caudal one occurring at about $3.5 \mathrm{~cm}$ from the rostral one; while Rashid and Kausar (2005) reported 4 incisors teeth and a canine (I 4, C 1,) occurring at about 1.25 inches from the fourth incisor. This controversy is due to the fact that the canine like-shape first premolar tooth is considered either as canine by Rashid and Kausar (2005) or as a second canine by Chaurasia, Tiwari, Pandey et al. (2010). Our arguments about this controversy are in accordance with the description of Lesbre (1903), Smuts and Bezuidenhout (1987) and Yahaya, Olopade and Kwari (2011). In the lateral view of the mandible, two mental foramina (Foramina mentalia) can be seen; a rostral one which corresponds to that found in other domestic mammals at the level of the first premolar 1, occasionally accompanied by an accessory one, and a caudal mental foramen frequently located ventrally to the junction of the first and the second molar teeth. This second foramen constitutes the first opening of the mandibular canal (Canalis mandibulae) in this species, giving passage to a long branch of the inferior alveolar nerve (Nervus alveolaris inferior) and to the homonymous artery and vein. The ramus mentalis rostralis of the inferior alveolar artery emerges from the rostral mental foramen. This ramus was reported to be always larger in one side (BADAWI, EL-SHAIEB and KENAWY, 1977). However, we did not notice any differences in the size of this ramus nor in width of the rostral mental foramen of both sides. Similarly, two mental foramina were reported in lama (GALOTTA and GALOTTA, 1994) and many others mammals such as carnivores and swine (GETTY, 1975a). There are also other small particular holes at the dorsal border of the molar part and behind the last molar tooth which gives passage to a little branch coming from the same inferior alveolar nerve (Figure 19).

The ramus of the mandible is convex and shows a particular very strong and hook-shaped process: the angular process (Processus angularis) which presenting medially a tubercle. This angular process was previously described by Chauveau (1879) in dromedary camel and by Lesbre (1903) in Bactrian camel; and also by Galotta and Galotta (1994) in lama. Similar angular process exists also in dog and rabbit (Barone, 1976). The Condylar process (Processus condylaris) of camel mandible is markedly transversally stretched and shows two articular surfaces: a flattened and almost convex caudal surface and a laterally extended and much more convex rostro-dorsally surface. The Coronoid process (Processus coronoideus) is well developed, thick and vertical, surrounding the bone area of the lateral pterygoid muscle (Musculus Pterygoideus lateralis) termination: Fovea pterygoidea. The area of termination of the medial pterygoid muscle (Musculus Pterygoideus medialis): Fossa pterygoidea is larger and occupy a ventral position. Rostro-dorsally appears the mandibular foramen (Foramen mandibulae) which continues below by a particular sulcus mylobyoideus appearing as a special groove covered by a thin and large long bony specula forming an opened canal (Figure 20). Similar description was reported by Chauveau (1879) in the dromedary camel and by Lesbre (1903) in the Bactrian camel. Our careful dissection of this part shows that this canal constitutes the pathway of the ramus mylobyoideus of the inferior alveolar artery and the homonym branch of inferior alveolar nerve. There are two other large muscle endings zones in the ramus of the mandible, one the lateral side, less deeper but larger, the masseteric fossa (Fossa masseterica) occupied by masseter muscle and the other on the caudal side, a thin surface on the Angulus mandibulae corresponding to the angular insertion of the digastric muscle (Musculus digastricus): pars occipitomandibularis usually described by the International 
committee on Veterinary Gross Anatomical Nomenclature (2005, Nomina Anatomica Veterinaria (NAV)) in the horse.

\subsection{Hyoid apparatus}

The hyoid apparatus is an assembly of bones and fibrocartilage pieces attached to the temporal bone and suspended to the cranium base. Unlike Chauveau (1879) who considered the camel hyoid bone as similar to that in cattle, we found that this apparatus (Figure 2l) is very different from that of other domestic mammals and that it is especially characterized by

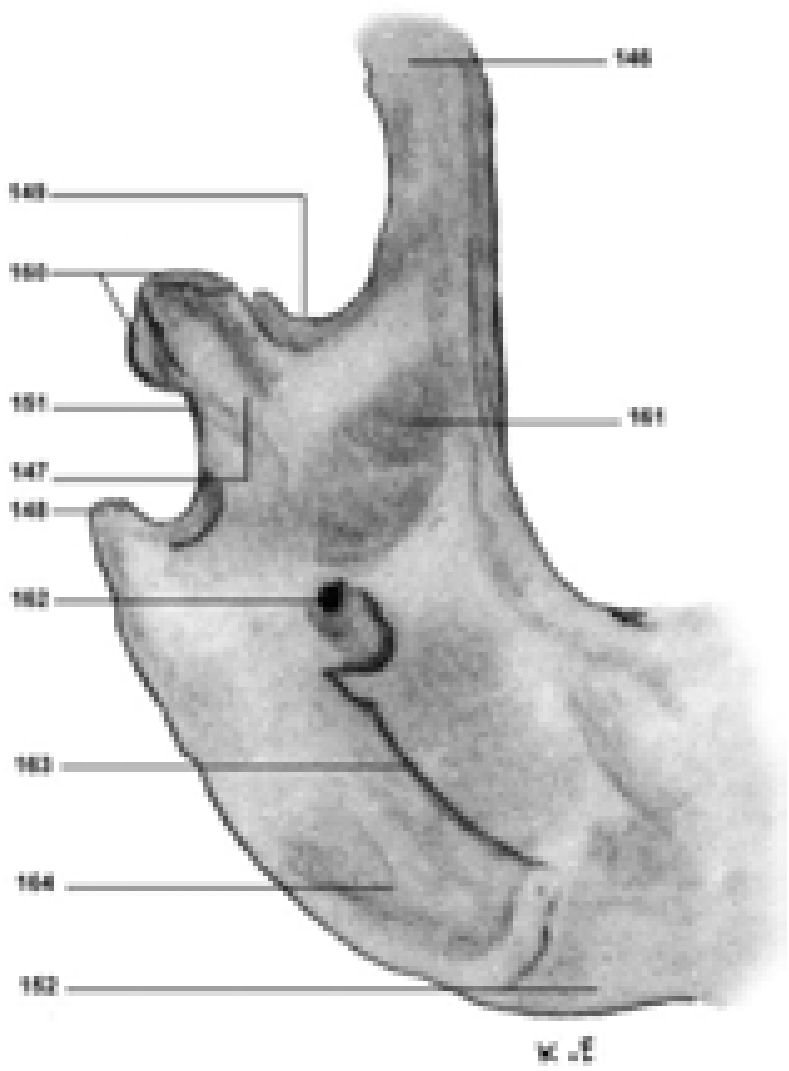

Figure 20. Medial view of the ramus of the left mandible of adult male (See Appendix A for definitions).

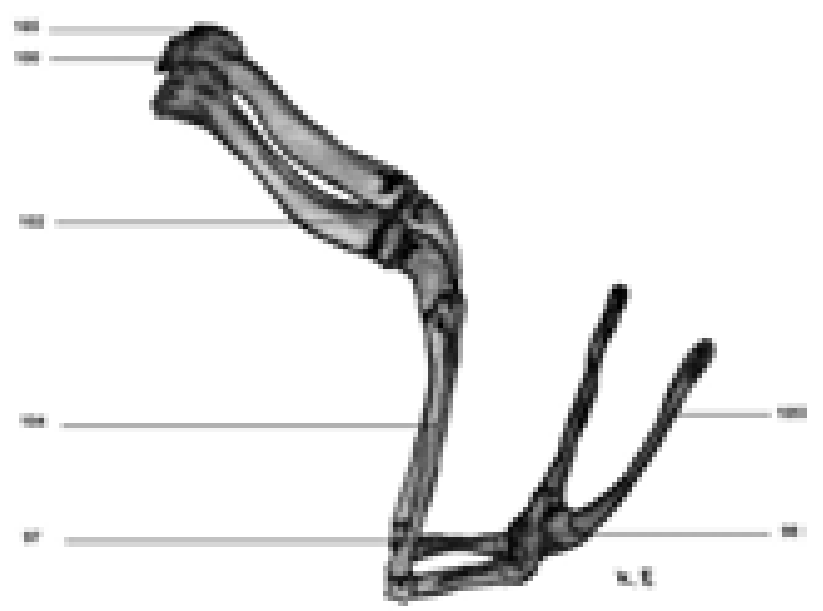

Figure 21. Lateral view of the hyoid apparatus of adult male (See Appendix A for definitions). a great degree of mobility. Indeed, the lingual process of the Basibyoideum of the camel hyoid apparatus is totally absent and the Ceratobyoideum which is extended by a well-developed dorsal part of the apparatus is brief. Thus the Epibyoideum is peculiarly very long and as higher as the Stylobyoideum. The inter-bone cartilage linking these two segments is also very large. The Stylobyoideum is taller and presents a prominent Angulus, and ends within a Tympanobyoideum which enters the deep fossa of the temporal vaginal process. As reported above, the elevated edges of this deep fossa seem to reduce excess movements of the apparatus. These peculiarities of the hyoid apparatus seem to be a camel specificity, as far as no such features were described in other domestic mammals even in closer species such as the lama.

Indeed, Galotta and Galotta (1994) have shown in an atlas that the Epibyoideum is less long than the Stylohyoideum and that the cartilage linking the two segments is very brief and the dorsal extremity of the stylobyoideum shows a rostral and a caudal angle similar to those observed in the horse.

\section{Conclusion}

Throughout this paper, besides revealing several peculiarities of the camel skull, we have revised completely the available data about the head skeleton of the camel focusing especially on some reports by shedding some lights about some reports but also by describing age related differences. Finally, a special interest was given to the skull foramina to elucidate the vessels and nerves pathways. The overall outcome data of this work constitutes a specific anatomical reference and contributes to a good knowledge of this species. On the other hand, these data could be useful in different fields such as osteo-archeology, evolution studies, basic and applied anatomy of the camel.

Acknowledgements: The authors thank Dr. Aziz Marhaban and colleagues of the slaughterhouse of Rabat, all staff of the Comparative Anatomy Unit, Dr. Bouâouda Hanan, Dr. Al Harf Adil, Pr. Piro Mohamed and Pr. Ahmed Ouhsine for their kind help. This work was supported by the National Center of Scientific and Technical Research (CNRST: URAC-49).

\section{References}

ALSAFY, MAM., EL-GENDY, AAS. and ABUMANDOUR, MMA. Computed tomography and gross anatomical studies on the head of one-humped camel (Camelus dromedarius). The Anatomical Record, 2014, vol. 297, n. 4, p. 630-642. PMid:24639077. http://dx.doi. org/10.1002/ar.22865.

AL-SAGAIR, O. and ELMOUGY, SA. Post-natal development in the linear and tric morphometrics of the camelidae skull. Anatomia, Histologia, Embryologia, 2002, vol. 31, n. 4, p. 232-236. PMid:12196266. http://dx.doi.org/10.1046/j.1439-0264.2002.00401.x.

BADAWI, H., EL-SHAIEB, M. and KENAWY, A. The Arteria maxillaris of the camel (Camelus dromedarius). Anatomia, Histologia, Embryologia, 1977, vol. 6, n. 1, p. 21-28. PMid:577117. http:// dx.doi.org/10.1111/j.1439-0264.1977.tb00417.x.

BARONE, R. Anatomie comparée des mammifêres domestiques: ostéologie. Paris: Vigot, 1976. p. 75-329.

BENGOUMI, M. and FAYE, B. Adaptation du dromadaire à la déshydratation. Sécheresse, 2002, vol. 13, p. 121-129.

BOUÂOUDA, H., ACHAÂBAN, MR., OUASSAT, M., OUKASSOU, M., PIRO, M., CHALlET, E., EL ALlALI, K. and PÉVET P. 
Daily regulation of body temperature rhythm in the camel (Camelus dromedarius) exposed to experimental desert conditions. Physiological Reports, 2014, vol. 2, n. 9, p. 1-16.

CHAURASIA, S., TIWARI, Y., PANDEY, A., KUMAR, V. and MALIK, MR. Biometry of mandible of camel (Camelus dromedarius). International Journal of Molecular Biology, 2010, vol. 1, n. 1, p. 2528. http://dx.doi.org/10.9735/0976-0482.1.1.25-28.

CHAUVEAU, A. Traité D'anatomie comparée des animaux domestiques. Paris: Baillière JB et Fils, 1879. p. 46-91.

EL ALLALI, K., ACHAÂBAN, MR., BOTHOREL, B., PIRO, M., BOUÂOUDA, H., EL ALLOUCHI, M., OUASSAT, M., MALAN, A. and PÉVET, P. Entrainment of the circadian clock by daily ambient temperature cycles in the camel (Camelus dromedarius). American Journal of Physiology. Regulatory, Integrative and Comparative Physiology, 2013, vol. 304, n. 11, p. Rl044-R1052. PMid:23485867. http:// dx.doi.org/10.1152/ajpregu.00466.2012.

GALOTTA, DR. and GALOTTA, JM. Esqueleto de la IIama ( Lama glama) Atlas. In GALOTTA, JM. (Ed.). Excerta anatómica camelidae. Buenos Aires: Fundación Camélidos Sudamericanos, 1994. p. 11-13

GETTY, R. Porcine. In GETTY, R. (Ed.). Sisson and grossman's the anatomy of domestic animals. Philadelphia: Saunders WB, 1975a. p. 1231-1244, vol. 2.

GETTY, R. Ruminants. In GETTY, R. (Ed.). Sisson and grossman's: the anatomy of domestic animals. Philadelphia: Saunders WB, 1975b. 768 p, vol. 1 .

HOWELL, AB. and STRAUS JUNIOR, WL. Note on the spinal accessory nerve of long-necked ungulates. In Proceedings of the Zoological Society of London, 1934. London: Zoological Society of London, 1934. p. 29-32.

INTERNATIONAL COMMITTEE ON VETERINARY GROSS ANATOMICAL NOMENCLATURE. Nomina anatomica veterinaria - NAV. Hannover, Columbia, Ghent, Sapporo: Editorial Committee, 2005.

JINHA, AE. Article 50 million: an estimate of the number of scholarly articles in existence. Learned Publishing, 2010, vol. 23, n. 3, p. 258263. http://dx.doi.org/10.1087/20100308.

LESBRE, MF-X. Recherches anatomiques sur les camélidés archives du Museum d'Histoire naturelle tome huitième. Lyon: Henri Georg, 1903. p. 196.

MÜLLER, HJ. Beobachtungen an nerven und muskeln des halses der tylopoden. Zeitschrift für anatomie und entwicklungsgesehiehte, 1962, vol. 123, p. 155-173.

OLOPADE, JO., ONWUK, SK., KWARI, HD., ABUBAKAR, UA. and SHAWULU, JC. Bilateral opening in the nasal bones of goat in Nigeria. Brazilian Journal of Morphological Sciences, 2006, vol. 23, p. 363-368.

RATHINASABAPATHY, G. and RAJENDRAN, L. Mapping of world-wide camel research publications: a scientometric analysis.
Journal of Library, Information and Communication Technology, 2013, vol. 5, n. 1-2, p. 35-40.

RASHID, RD. and KAUSAR, R. Comparative gross anatomical studies of the skull of one humped camel (Camelus dromedarius). Pakistan Veterinary Journal, 2005, vol. 25, p. 205-206.

SCHMIDT-NIELSEN, K., SCHMIDT-NIELSEN, B., JARNUM, SA. and HOUPT, TR. Body temperature of the camel and its relation to water economy. The American Journal of Physiology, 1957, vol. 188, n. 1, p. 103-112. PMid:13402948.

SHAWULU, JC., KWARI, HD. and OLOPADE, JO. Morphology of the bones of the skull in the Sahel Ecotypes of Goats (Capra hircus) in Nigeria. Journal of Veterinary Anatomy, 2011, vol. 4, p. 1-13.

SISSON, S. and GROSSMAN, JD. Anatomy of the domestic animals. Philadelphia: Saunders WB, 1953. 137 p.

SMUTS, MS. and BEZUIDENHOUT, AJ. Anatomy of the Dromedary. Oxford: Clarendon Press, 1987. p. 1-9.

WILSON, RT. The Camel. London: Longman Group, 1984. 223 p.

WYSOCKI, J. Morphology of the temporal canal and postglenoid foramen with reference to the size of the jugular foramen in man and selected species of animals. Folia Morphologica, 2002, vol. 61, n. 4, p. 199-208. PMid:12725485.

YAHAYA, A., OLOPADE, JO. and KWARI, HD. Clinical implications of craniometric indices of the one-humped camel (Camelus dromedarius) to oral health and clinical regional anaesthesia of the head. J Vet Anat, 2011, vol. 4, n. 1, p. 19-31.

YAHAYA, A., OLOPADE, JO., KWARI, HD. and HAMBALI, IU. Some aspects of the maxillofacial and mandibular anatomy of camels (Camelus dromedaries) in Nigeria. Journal of Morphological Science, 2012a, vol. 29, p. 140-143.

YAHAYA, A., OLOPADE, JO., KWARI, HD. and WIAM, IM. Osteometry of the skull of one-humped camels Part I: immature animals. Italian Journal of Anatomy and Embryology, 2012b, vol. 117, n. 1, p. 23-33. PMid:22893997.

YAHAYA, A., OLOPADE, JO., KWARI, HD. and WIAM, IM. Investigation of the osteometry of the skull of the one-humped camels Part II: sex dimorphism and geographical variations in adults. Italian Journal of Anatomy and Embryology, 2012c, vol. 117, n. 1, p. 34-44. PMid:22893998.

YAHAYA, A., OLOPADE, JO. and KWARI, HD. Morphological analysis and osteometry of the foramen magnum of the one-humped camel (Camelus dromedarius). Anatomia Histologia Embryologia, 2013, vol. 42, n. 2, p. 155-159. 
Appendix A. Compound legend of Figure 1-21.

1, External occipital protuberance; 2, Occipital bone; 3, Squamous suture; 4, Temporal bone; 5, Planum parietale; 6, Parieto-frontal suture; 7, Zygomatic arch; 8, Frontal bone; 9, Infra-trochlear notch; 10, Fronto-nasal suture; 11, Maxillary bone; 12, Nasal bone; 13, Median process of the nasal bone; 14, Lateral process of the nasal bone; 15, Nasal process of the vomer bone; 16, Palatine fissura; 17, Interincisive fissura; 18, Temporal fossa; 19, External sagittal crest; 20, Parietal bone; 21, Temporal line; 22, Frontal suture; 23, Supra-orbital foramina; 24, Lacrimal, fontanel or Fronto-naso-maxillary foramen, 25; Infra-orbital foramen;26, Naso-maxillary suture, 27; Nasal suture; 28, Nasal process of incisive bone; 29, Body of incisive bone; 30, Lateral spheno-palatine foramen, 31; Orbit; 32, Zygomatic process of frontal bone; 33, Zygomatic process of temporal; 34, External acoustic meatus; 35, Occipital condyle; 36, Foramen magnum; 37, Pterygoid process of basi-sphenoid; 38, Temporal process of zygomatic bone; 39, Perpendicular part of palatine bone; 40, Frontal process of zygomatic bone; 41, Maxillary foramen; 42, Accessory maxillary foramen; 43, Lacrimal foramen; 44 and 45 , Convexity and concavity of external sagittal crest; 46, Nuchal crest; 47, Mastoid crest; 48, Stylomastoid foramen; 49, Optic foramen; 50, Maxillary tuberosity; 51, Muscular process; 52, Orbitorotundum foramen; 53, Lacrimal bone; 54, Alveolar process of maxillary bone; 55, Orbital opening of the supra-orbital canal; 56, Ethmoidal foramen; 57, Caudal lacrimal process; 58, Zygomatic arch; 59, Medial spheno-palatine foramen; 60, Caudal palatine foramen; 61, Origin of the zygomatic process of frontal bone; 62, Orbital process of zygomatic bone; 63, Pterygoid crest; 64, Optic duct; 65, Canine fossa; 66, Junction point of nasal maxilla and incisive bones; 67, Nasal process of the maxilla; 68, Jugular process; 69, Opening of the hypoglossal canal and condylar canal;70, Muscular tubercle ; 71, Basi-sphenoid body; 72, Sphenoid process of vomer; 73, Sulcus $n$. canalis pterygoideus; 74, Vomer; 75, Pterygo-palatine fossa; 76, Palatine bone; 77, Transverse palatine suture; 78, Accessory palatine foramina; 79, Ventral condylar fossa; 80, Basilar process of the occipital bone; 81, Jugular foramen; 82, External opening of the carotid canal (Carotid foramen); 83, Lacerate foramen; 84, Foramen ovale; 85, Pterygoid hamulus of the pterygoid bone; 86 , Lateral hamulus of the pterygoid process of the basi-sphenoid body; 87 , Nasal spine of palatine bone; $\mathbf{8 8}$, Molar III tooth of maxillary bone; 88', Molar III tooth of mandible; $\mathbf{8 9}$, Median palatine suture; 90, Palatine foramen; 91, Premolar-I tooth of maxillary bone ; 91', Premolar-I tooth of mandible ; 92, Canine tooth of maxillary bone; 92', Canine tooth of mandible; 93, Incisor tooth of maxillary bone; 93', Incisor III of mandible; 94, Squamous portion of the temporal bone; 95, Retro-articular process; 96, Styloid process; 97, Cerato-hyoideum; 98, Basi-hyoideum; 99, Fossa of styloid process; 100, Tympano-hyoideum; 101, Tympanic bulla; 102, Stylo-hyoideum; 103, Choanae; 104, Epihyoideum; 105, Thyro-hyoideum; 106, Tympano-occipital fissura; 107, Pterygoid fossa; 108, Spheno-occipital suture; 109, Horizontal part of palatine bone; 120, Dorsal condyloid fossa; 121, Nuchal tubercle; 122, Ethmoidal fossa; 123, Fossa piriformis; 124, Optic fossa; 125, Crista galli; 126, Ethmoid bone; 127, Hypophyseal fossa; 128, Temporal meatus; 129, Groove of maxillary nerve; 130, Internal sagittal crest; 131, Perpendicular plate of ethmoidal bone; 132, Groove of cavernous sinus; 133, Dorsum sellae; 134, Internal occipital protuberance; 135, Petrosal crest; 136, Internal acoustic meatus; 137, Ventral meatus of nasal cavity; 138, Ventral nasal concha; 139, Dorsal meatus of nasal cavity; 140, Dorsal nasal concha; 141, Middle nasal concha; 142, Frontal sinus; 143, Middle meatus of nasal cavity; 144, Ethmoturbinal; 145, Cerebellar fossa; 146, Coronoid process of mandible; 147, Condylar process of mandible; 148, Angular process; 149, Mandibular notch; 150, Caudal mental foramen;151, Collum mandibulae; 152, Angle of mandible; 153, Rostral mental foramen; 154, Incisor I; 155, Incisor II; 156, Premolar II of maxillary bone; 156', Premolar II of mandible; 157, Premolar III of maxillary bone; 158, Molar I of maxillary bone; 158', Molar I of mandible; 159, Molar II of maxillary bone; 159', Molar II of mandible; 160, Articular surfaces of condylar process of mandible; 161, Fovea pterygoidea; 162, Mandibular foramen; 163, Sulcus mylohyoideus; 164, Fossa pterygoidea of mandible; 165, Angulus stylohyoideus; 166, Articular tubercle; 167, Glenoidal cavity; 168, Medial retroarticulare foramen; 169, Lateral retroarticulare foramen; 170, Foramen mastoideum; a, Occipital artery; b, common carotid artery; c, Internal carotid artery; d, External carotid artery ; e, Condyloid artery; f, Temporal facial trunk; g, Caudal auricular artery; h, Temporal superficial artery; i, Maxillary artery; $\mathbf{j}$, Lingual artery; $\mathbf{k}$, Vagus nerve; 1 , Cervical sympathetic nerve; m, Cranial cervical ganglion; n, Hypoglossal nerve; o, Glosso-pharyngeal nerve; p, Sympathetic fibers coming from the cranial cervical ganglion. 